\title{
"Por tierra nada conocida". El diario inédito de José de Cañizares a la Alta California (1769)
}

Salvador Bernabéu Albert

Escuela de Estudios Hispano-Americanos (CSIC)

Este artículo es un análisis y transcripción del diario de José de Cañizares, de Velicatá (Baja California) a San Diego (Alta California) en el año 1769. Cañizares, un joven piloto español, fue encargado por el visitador general José de Gálvez de escribir un diario y tomar observaciones astronómicas del camino entre ambos puntos. Con el tiempo llegó a ser uno de los grandes exploradores del litoral del Pacífico Norte. La copia utilizada se guarda en el Archivo General de Indias, de Sevilla, y es la primera vez que se publica en castellano.

Palabras claves: Exploración, Frontera, California, José de Gálvez, Santa Expedición, Océano Pacífico.

This article is an analysis and transcription of José de Cañizares' diary from Velicatá (Baja California) to San Diego (Alta California) in the year 1769. Cañizares, a young Spanish pilot, was enchanged by José de Gálvez, general visitor of New Spain, to write a diary and take astronomical observations. The author was to become one of the greatest mariners of the North Pacific coast. The copy from which this translation was made is in the Archivo General de Indias, Sevilla, and this is the first edition in its original language.

Keywords: Exploration, Frontier, California, José de Gálvez, Sacred Expedition, Pacific Ocean.

Uno de los principales resultados de la visita general de José de Gálvez a la Nueva España fue la expansión fronteriza que impulsó en el noroeste del virreinato. En poco más de tres años (1768-1771), el impetuoso malagueño fundó el puerto de San Blas, en Nayarit, visitó el sur de la península de Baja California, organizó las expediciones marítimas y terrestres que ocuparon los puertos de San Diego y Monterrey, y recorrió amplias áreas de Sonora hasta que una enfermedad lo obligó a retornar a México. En esta expansión, la citada ocupación de San Diego y de Monterrey, futura capital de la Alta o Nueva California, se convirtió en un hito que el virrey y el visitador difundieron ampliamente para compensar otros fracasos de su excursión norteña. La Corona, los funcionarios virreinales y los franciscanos, que habían sustituido a los jesuitas en 1768 en la península bajacaliforniana, se concentraron en las fundaciones de la Alta o Nueva California (de San Diego a San Francisco) y empezaron a barruntar 
su salida de la Antigua California. Surgió entonces el problema de la ocupación de la enorme "brecha" abierta entre una y otra Californias: un territorio intermedio, situado entre las nuevas misiones franciscanas y las antiguas de la Compañía de Jesús, bautizada como La Frontera, que se convirtió en una de las áreas más abandonadas y desconocidas del gran Norte mexicano. Esta demarcación sería heredada por la Orden de Santo Domingo, religiosos que sustituyeron a los franciscanos (1773) en las misiones de la península de Baja California, convirtiéndose en los fundadores de una nueva región misional (Rosario, 1774; Santo Domingo, 1775; San Vicente Ferrer, 1780) y en los engarzadores de ambas Californias (San Miguel Arcángel, 1787, levantada por el valenciano fray Luis de Sales). Pero fue una ocupación precaria que siempre tuvo en jaque a las autoridades virreinales, obligando a nuevas fundaciones para asegurar el camino real (Santo Tomás de Aquino, 1791; El Descanso, 1817) y para contener a las rancherías indígenas que habitaban la zona del Colorado (San Pedro Mártir de Verona, 1794; Santa Catalina, 1797; y Nuestra Señora de Guadalupe del Norte, 1834).

Este enorme espacio, habitado por varios pueblos indígenas pertenecientes a la familia de los yumanos occcidentales (kumiai, pa-itai, kiliwa, cochimís), ha sido la región menos conocida historiográficamente de toda la California, desequilibrio que viene siendo superado en los últimos años gracias a la publicación de varias libros y la edición de las crónicas y diarios de los misioneros, exploradores, jefes militares y viajeros modernos ${ }^{1}$. En esta tarea de recuperación de las fuentes históricas bajacalifornianas se enmarca este trabajo, dividido en dos partes: una introducción histórica y la transcripción del diario de José de Cañizares, pilotín que participó en la primera expedición que recorrió el norte de la península en 1769 cuando los obedientes súbditos de Carlos III se disponían a ocupar los puertos de San Diego y Monterrey. El diario ha permanecido inédito en castellano, a pesar de ser una fuente fundamental para el estudio de la Baja California, laguna que ahora llenamos, pues aunque el viaje era conocido gracias a otro diario, escrito por el franciscano Juan Crespi, el que ahora publicamos lo completa en algunas áreas y nos ofrece datos inéditos de gran interés

1 Un balance de las aportaciones recientes sobre la historia de Baja California en mi prólogo a la obra de Albert B. Nieser: Las fundaciones misionales dominicas en Baja California, 1769-1822, Universidad Autónoma de Baja California, Mexicali, 1998, págs. 7-47; y en el estudio introductorio de la edición de fray Luis de Sales: Noticias de la provincia de Californias, Fundación Barca-Museo de Historia de Ensenada-Seminario de Historia de Baja California, Ensenada, 2003, págs. 11-62. 
para el estudio de la naturaleza y las rancherías indígenas. En resumen, este trabajo ofrece la primera edición en castellano de un diario, hasta ahora muy citado, pero escasamente utilizado por los historiadores. Antes de transcribirlo, he realizado un estudio del marino José de Cañizares, figura muy desconocida por la dispersión de datos y las dificultades de completar sus numerosos viajes y trabajos al servicio de la Corona en el Pacífico. Fue un hombre que supo escalar puestos en la difícil y elitista carrera naval, que en gran medida "se hizo a sí mismo", pues empezando como pilotín en San Blas, ascendió a teniente de fragata de la Real Armada. Su azarosa vida nos servirá para introducirnos en la "trabajosa" presencia de España en el Noroeste de América en la segunda mitad del siglo XVIII. A continuación, estudiaré a grandes líneas la conocida como "La Santa Expedición" (17691770), que ocupó los puertos de San Diego y Monterrey, y sus resultados documentales, todo ello como pórtico a la edición del diario de Cañizares a la "tierra nada conocida", pues esta región de América sólo se había contemplado desde la lejanía por los navegantes (Cabrillo, Vizcaíno y los pasajeros del galeón de Manila en el tornaviaje). Evidentemente, ese "desconocimiento" era sólo para los viajeros occidentales, pues para los indígenas, que habitaban el área desde hacía siglos, el territorio era suficientemente conocido y trillado.

\section{José de Cañizares: trabajador del mar}

Desconozco el lugar de nacimiento de José de Cañizares, pero probablemente fue en Sevilla, ciudad en donde se formó, concretamente en el Colegio Seminario de San Telmo, institución local dedicada a enseñar las artes náuticas a los jóvenes huérfanos. De este centro salió el 20 de marzo de 1762, aunque no completó los estudios. Se examinó de pilotín de particulares el 23 de junio de 1765 en la Academia de Cádiz y fue admitido con este cargo en el departamento de San Blas de Nayarit (México) el 24 de mayo de 1768. No he encontrado ningún dato que esclarezca cómo y cuándo realizó el viaje de la península al virreinato. Lo más probable es que desembarcase en Veracruz, y desde allí se trasladase por tierra hasta Nayarit, en la costa del Pacífico. Pero no hay documentos — hasta ahora- que nos den luz sobre sus actividades durante los tres años que transcurrieron entre su examen de pilotín y su incorporación a la expedición organizada por José de Gálvez para ocupar los puertos de San Diego y Monterrey. Bajo las 
órdenes del capitán Fernando Javier Rivera y Moncada, comandante del presidio de Loreto, José de Cañizares partió de la misión de San Fernando de Velicatá (Baja California) el 24 de marzo de 1769 con 25 soldados, 3 muleros, 42 indios cristianizados de las misiones bajacalifornianas y el misionero fray Juan Crespi. Su cometido era realizar observaciones astronómicas en distintos puntos del itinerario para elaborar futuros mapas. Además, José de Gálvez le ordenó redactar un diario de la expedición, que el joven marino escribió y fue enviado a la corte por el virrey marqués de Croix el 27 de julio de $1770^{2}$. Más adelante estudiaré con algún detenimiento esta expedición, por lo que seguiré esbozando su biografía.

Tras participar en la toma de posesión del puerto de San Diego, Cañizares regresó a San Blas el primero de agosto de 1770 a bordo del paquebot San Carlos, barco capitaneado por Vicente Vila, con el empleo de pilotín. Tras su llegada al puerto nayarita, participó en el sondeo del mismo junto a otros compañeros. Un año más tarde navegó al presidio de Loreto (Baja California) en el paquebot San Carlos, recibiendo 35 pesos de sueldo al mes $^{3}$. La misma cantidad siguió disfrutando en el citado barco, que fue destinado a San Diego en 1772 con diversas provisiones, bajo las órdenes de Miguel del Pino ${ }^{4}$. En el viaje de regreso condujo a fray Junípero Serra, que fue a la ciudad de México para resolver distintos problemas que aquejaban a las misiones californianas, como la inseguridad en el abastecimiento y las malas relaciones con el comandante de Monterrey, el capitán de la Compañía de Voluntarios de Cataluña Pedro Fages 5 . De nuevo como segundo piloto del San Antonio, capitaneado por Juan Pérez, José de Cañizares navegó en 1773 al presidio de Loreto tras intentar en vano anclar en los nuevos establecimientos de la Alta California. A la altura del Cabo de San Lucas (en el extremo sur de la península), los pilotos encontraron roto el timón del barco, teniendo que refugiarse en Puerto

2 El marqués de Croix a Julián de Arriaga, México, 27 de julio de 1770, en Archivo General de Indias (AGI, en adelante), México, Guadalajara, 417.

3 Trillo al marqués de Croix, San Blas, 29 de enero de 1771, en Archivo General de la Nación (AGN, en adelante), Marina, 30, fols. 242-243.

4 Conocemos bien esta navegación gracias al: "Diario de navegación que con el auxilio divino espera hacer don José de Cañizares, segundo capitán y piloto del paquebot de Su Majestad San Carlos, el cual sale a hacer viaje a los puertos de Monterrey y San Diego en la costa occidental de la California al mando del capitán y piloto don Miguel del Pino ... 1772”, en AGN, Californias, 35, fols. 131-191.

5 Cañizares tuvo una disputa con el gobernador por la tardanza de éste en entregarle los pliegos que debía conducir a San Blas. Fages a Bucareli, San Diego, 17 de octubre de 1772, en AGN, Californias, 66, fols. 185-188. 
Escondido, en las inmediaciones de Loreto. En este puerto, una junta de oficiales determinó desembarcar los víveres y regresar a San Blas para dar cuenta a las autoridades del grave contratiempo, ya que la ausencia del auxilio anual era muy arriesgado para los precarios establecimientos altacalifornianos ${ }^{6}$.

La licencia de varios pilotos obligó a las autoridades a entregar el paquebot San Antonio a Cañizares en 1774 para conducir víveres y efectos a Monterrey, a pesar de que fray Junípero Serra lo considerase muy joven para viajar como único piloto. El San Antonio levó anclas el 21 de abril con sus bodegas llenas de bastimentos, si bien tuvo que detenerse durante algún tiempo en el puerto de Mazatlán (Sinaloa) debido a los vientos contrarios. El 3 de junio llegó a Monterrey, en donde se encontró con su compañero Juan Pérez, quien con la nueva fragata Santiago se disponía a explorar la costa del Noroeste por orden de Carlos III, iniciando la presencia española al norte de San Francisco. Siguiendo las instrucciones que llevaba, José de Cañizares entregó a Juan Pérez varios pliegos que conducía y se dirigió al puerto de San Diego, donde entregó varias cargas para el presidio y la misión. Estas entregas fueron fundamentales para la sobrevivencia de los primeros soldados y misioneros, por lo que sería importante estudiar los trabajos de este grupo de marinos. Cumplidos sus encargos, el San Antonio ancló en San Blas el 30 de agosto de 17747, llevando como pasajeros al capitán Fages y a los franciscanos Juan Prestamero, Ramón Usón y Domingo Juncosa. Como recompensa por sus esfuerzos, el virrey Bucareli le comunicó su nombramiento de segundo piloto del Departamento el 12 de enero de 1774, otorgándole la antigüedad sobre todos los demás.

El año 1775 fue decisivo para la actividad exploratoria de los españoles en el Pacífico Septentrional. Un año antes, varios oficiales de la Armada llegaron a San Blas (Juan Manuel de Ayala, Juan Francisco de la Bodega y

6 El gobernador Felipe Barri comunicó a nuestro marino la imposibilidad de enviar los víveres a la Alta California por la falta de recuas para atravesar la árida península. Barri a Pérez y Cañizares, Puerto Escondido, 28 de junio de 1773, en AGN, Californias, 66, fol. 378. La gravedad de este viaje impulsó las gestiones de Serra ante el virrey Bucareli, al que presentó una "Representación" en 32 puntos, fechada el 13 de marzo de 1773 (AGI, Guadalajara, 514). Este texto ha sido editado por Salustiano Vicedo, O.F.M. (editor): Escritos de fray Junípero Serra, Apóstol y Civilizador, Petra, t. II, págs. 78-103.

7 José de Cañizares: "Diario de la navegación que acaba de hacer el paquebot de Su Majestad el Príncipe al puerto de Monterrey al cargo de su capitán y piloto don ... en este año de 1774. Cuarto viaje", en AGN, Californias, 35, fols. 93-130. En el viaje avistó la isla de Socorro el 12 de abril y un día antes la de San Benedicto, isla perteneciente al grupo de las Revillagigedo, como la anterior, que Cañizares bautizó con el nombre de San Juan Nepomuceno. 
Cuadra, Bruno de Heceta, Diego Choquet de Isla, Fernando Bernardo de Quirós, Ignacio Arteaga y Miguel Manrique), redoblando las actividades y multiplicando los destinos de los viajes. Los pilotos —anteriormente imprescindibles - pasaron a un segundo plano, pero al estar experimentados en las navegaciones de estos mares, sus trabajos y consejos fueron muy importantes. Cañizares fue piloto del paquebot San Carlos, que abasteció el puerto de Monterrey en 1775 mientras la fragata Santiago y la goleta Sonora exploraban las costas del Noroeste en una nueva búsqueda frenética de asentamientos rusos. Nuestro marino sirvió bajo las órdenes del teniente de fragata Juan de Ayala, quien estuvo impedido y postrado la mayor parte del viaje debido a un accidente. El 26 de junio, el paquebot ancló en Monterrey y el 27 de julio siguiente penetró en la bahía de San Francisco, magnífico puerto descubierto en 1770. Tras una detenida exploración, Cañizares dibujó el primer mapa completo, perfilando sus numerosas bahías e islas interiores ${ }^{8}$. Además, nuestro marino escribió una importante memoria en la que elogió las cualidades naturales de San Francisco y destacó las posibilidades para sostener una colonia9. Por estos trabajos, la Corona lo premió con sucesivos ascensos: graduado de alférez de fragata el 28 de febrero de 1776 y primer piloto el 12 de enero de $1777^{10}$. El teniente Juan de Ayala destacó: "su acostumbrada honradez" y "una gran inteligencia en su facultad"

Cañizares no tuvo descanso. En 1776 viajó como piloto en el San Carlos, bajo las órdenes del teniente Fernando Quirós, con la misión de abastecer San Francisco y Monterrey ${ }^{12}$, y el 28 de diciembre de 1776 partió rumbo a Lima acompañando a Juan Francisco de la Bodega y Cuadra, quien tenía la orden de adquirir un barco destinado al departamento de San Blas. Bodega se decidió por una fragata, llamada Favorita, que fue refor-

8 El original se guarda en el AGI, México, 305. El mapa fue grabado en 1781 por Manuel Villavicencio, en México. Watson, Douglas S.: "The 1781 Cañizares Map of San Francisco Bay", en California Historical Society Quarterly, XIII, 1934, págs. 180-181. Sobre el mapa, véase Harlow, Neal: "The Maps of San Francisco Bay and the Town of Yerba Buena to One Hundred Years Ago", en The Pacific Historical Review, vol. XVI, n. ${ }^{\circ}$ 4, 1947, págs. 365-378.

9 José de Cañizares: "Descripción del nuevo puerto de San Francisco, situado por una prudente conjetura en la latitud norte de 37 grados 53 minutos y en la longitud occidental del meridiano de San Blas, 17 grados 10 minutos", en AGI, Estado, 20 (19).

10 Mourelle, "Nómina de pilotos ..." en AGI, Guadalajara, 520; y AGN, Marina, 62. Cañizares recibió cien pesos por sus trabajos en la formación de planos, mapas y cartas de San Francisco en 1776 y, tres años más tarde, Carlos III le concedió la licencia para casarse con Josefa López Portillo.

11 Ayala a Bucareli, San Blas, 9 de noviembre de 1775, en AGI, Estado, 20 (19).

12 Cañizares asesoró a las autoridades en la localización de lugares para levantar el presidio y la misión de San Francisco. 
mada, trabajos que supervisó Cañizares durante varios meses ${ }^{13}$. Finalmente, el 19 de diciembre de 1777, ambos marinos pusieron rumbo a San Blas, a donde llegaron el 21 de febrero de 1778. Además de numerosos repuestos para los barcos del departamento, la fragata condujo a cuatro pasajeros y a dos pilotines: José Tobar y Tamaríz y Juan Pantoja, pilotos que se incorporaron a la nómina del puerto nayarita.

En 1779, Cañizares participó en una nueva expedición al Noroeste tras ser nombrado primer piloto de la fragata Favorita; el capitán era su conocido Juan Francisco de la Bodega y Cuadra. El 11 de febrero, la fragata levó anclas, viajando en comandita con otro barco hasta que una tormenta los separó el 20 de abril. Con una diferencia de diez horas, volvieron a reunirse el 3 de mayo en el puerto de Bucareli, en cuyo paraje permanecieron hasta el 15 de junio. Cañizares sondeó el puerto entre el 1 y el 8 de junio y participó en otros trabajos de la expedición, que logró cartografiar buena parte de la costa de Alaska, trabajos que quedaron plasmados en una importante cartografía y en un diario que permanece inédito ${ }^{14}$. El 3 de junio de 1780, Carlos III lo nombró teniente de fragata y, meses más tarde, el 14 de noviembre de 1781, firmó su ascenso a alférez de navío.

En la década de los ochenta, Cañizares realizó nuevos viajes. Entre el 14 de marzo y el 27 de octubre de 1784 viajó con el paquebot San Carlos, alias El Filipino, a abastecer los presidios de San Francisco, Monterrey, Santa Bárbara y San Diego. En 1787, entre el 17 de junio y el 13 de diciembre, capitaneó la Favorita con destino a Monterrey, Santa Bárbara y San Diego, y un año más tarde, con el paquebot Nuestra Señora de Aránzazu, viajó de nuevo a los cuatro presidios altocalifornianos entre el 8 de julio y el 29 de diciembre de 1788, siendo el único barco que visitó la Alta California ese año. Casi al mismo tiempo, dos barcos españoles, la Princesa, al mando de Esteban José Martínez, y el San Carlos, capitaneado por Gonzalo López de Haro, lograron contactar con los rusos en Alaska y conocieron de primera mano el proyecto zarista de ocupar Nutka (isla de

13 La documentación de la compra y los arreglos de la Favorita se encuentra en AGN, Provincias Internas, 33; Provincias Internas, 212; y Marina, 21, fols. 43-84.

14 José de Cañizares: "Navegación que hace el alférez de fragata graduado y primer piloto don José de Cañizares desde el puerto de San Blas, situado en 21 grados, 30 minutos, de latitud Norte a los descubrimientos de la costa septentrional de Californias en la fragata de Su Majestad Nuestra Señora de los Remedios, alias la Favorita, de 39 codos de quilla y de manga 13 codos, calada de popa 14 pies y de proa 13, de la que es comandante el teniente de navío de la Real Armada y caballero del orden de Santiago, don Juan Francisco de la Bodega y Cuadra en conserva de la fragata de Su Majestad la Princesa, del mando del de la misma clase don Ignacio Arteaga, comandante de la expedición. Año de 1779", en AGI, Estado, 38. 
Vancouver) al año siguiente. Como consecuencia, los mismos barcos fueron enviados al citado puerto en 1789, siendo de nuevo Cañizares el encargado de abastecer con el paquebot Nuestra Señora de Aránzazu los presidios de la Alta California, antes de unirse a los barcos españoles en Nutka. Es decir, nuestro marino servía tanto para conducir alimentos y tropas, como para explorar nuevos puertos: era un experto en estos mares. Cañizares llegó a Nutka el 29 de julio, llevando una importante noticia: que los españoles abandonasen el puerto y regresasen a San Blas. Así lo realizaron, no dando tiempo a que llegase la contraorden de la corte española, que obligaría a los barcos de San Blas a ocupar Nutka por segunda vez ${ }^{15}$.

Los trabajos de Cañizares continuaron durante la presencia hispana en el conflictivo Nutka, puerto disputado por varias naciones. En 1792, Bodega y Quadra envió a la fragata Santa Gertrudis a San Francisco para conseguir alimentos, capitaneada por el comandante Alonso de la Torre. Entre las órdenes que le dio, estaba la de entrar en el estrecho de Fuca y reconocer minuciosamente la costa entre $\operatorname{los} 41^{\circ}$ y $\operatorname{los} 47^{\circ} \mathrm{N}$, para cuya comisión embarcó: "al teniente de fragata graduado don José de Cañizares, sujetos de instrucción y talento a quienes comisioné para la configuración de las montañas, arrumbamiento de la costa y descripción del terreno"16. Aunque los datos sobre las actividades de Cañizares durante los siguientes meses disminuyen, sabemos que certificó, como contador oficial de la fragata Princesa, los gastos realizados por Salvador Fidalgo en sus viajes (lo firma Cañizares en San Blas el 25 de abril de $1795^{17}$ ). El último viaje que conozco llevó a nuestro marino a San Francisco, Monterrey y San Diego con tropas y pertrechos entre el 6 de febrero y el 2 de julio de 1796. Capitaneaba la goleta Valdés. Su rastro desaparece de los archivos, desconociéndose el lugar y año de su fallecimiento. Su labor fue continuada por un hijo, llamado Francisco Antonio de Cañizares, que comenzó como meritorio de pilotos en 1796 y consiguió la graduación de pilotín en $1802^{18}$.

15 Un resumen de la actividad de los españoles durante estos años en Bernabéu Albert, Salvador: "España en el Noroeste. Navegantes y proyectistas en el siglo XVIII", en M. Palau et al., Nootka. Regreso a una historia olvidada, Ministerio de Asuntos Exteriores, Madrid, 1998, págs. 15-25. Las actividades de los ingleses han sido estudias por Cook, Warren: Flood Tide of Empire: Spain and the Pacific Northwest, 1543-1819, Yale University Press, New Haven and London, 1973.

16 Bernabéu Albert, Salvador (editor.): Juan Francisco de la Bodega y Quadra. El descubrimiento del fin del mundo (1775-1792), Alianza Editorial, Madrid, 1990, pág. 171.

17 Archivo General de Marina, Expediciones de Indias, leg. 31, exp. 1: "Superior Gobierno. Año de 1802", fols. 42v-43.

18 Fuster, Francisco: El final del descubrimiento de América. California, Canadá y Alaska (1765-1822), Universidad de Murcia, Murcia, 1997, pág. 519. 


\section{La Santa Expedición (1768-1770): los diarios.}

En 1770 apareció en México un impreso de dos hojas con el título: "Extracto de Noticias del puerto de Monterrey, de la misión y presidio que se han establecido en él con la denominación de San Carlos, y del sucesso de las dos expediciones de mar, y tierra que a este fin se despacharon en el año próximo anterior de 1769". El éxito de lectores (una segunda edición apareció antes de acabar el año ${ }^{19}$ ) estaba justificado por el impacto popular que tuvo la noticia, ya que la ocupación de la costa del Noroeste de América con una o varias colonias era un proyecto largamente acariciado desde mediados del siglo XVI. El puerto había sido demarcado por Sebastián Vizcaíno el 13 de diciembre de 1602, quien lo recomendó para levantar una colonia española tras explorarlo con varios de sus hombres. La bahía serviría para que el galeón de Manila se refugiase tras la larga navegación transpacífica, ya que Monterrey estaba situado en la altura donde los galeones divisaban el continente americano en su viaje hacia el este. La fundación de un establecimiento disminuiría la mortandad del navío, pues los pasajeros y tripulantes podían proveerse de alimentos frescos. Además, la costa se pondría bajo el dominio español, impidiendo el asentamiento de otra potencia extranjera en el litoral de California. Vizcaíno no era el primero en explorar la costa. En 1542 lo había hecho Juan Rodríguez Cabrillo, quien recorrió el litoral con dos naves, bautizando numerosas islas y bahías, entre ellas, la magnífica bahía de San Miguel, que más tarde Vizcaíno rebautizó como San Diego. Estos dos puertos (San Diego y Monterrey) se convirtieron en escalas míticas de la costa, que distintos virreyes y exploradores quisieron ocupar, aunque sin éxito, hasta el año 1769.

El responsable de esta "hazaña", aplazada en varias ocasiones, fue José de Gálvez, quien, a pesar de no ir personalmente a ocupar los dos puertos, se convirtió en el héroe de la jornada, pues había organizado y despachado personalmente la doble expedición terrestre y marítima que alcanzó la anhelada meta. Su interés por las costas californianas se remonta a los primeros meses de su llegada al virreinato con el nombramiento de

19 La segunda edición consta de ocho páginas en cuarto. También apareció en 1770. El "Extracto de Noticias" está transcrito en Mathes, Michael W. (ed.): Noticias y documentos acerca de las Californias, 1764-1795, José Porrúa Turanzas, Madrid, 1959, págs. 43-48; y en Cano, Angela et al.: Gaspar de Portolá. Crónicas del descubrimiento de la Alta California, 1769, Universidad de Barcelona, Barcelona, 1984, págs. 19-22. 
visitador general, pero fue la expulsión de los jesuitas en 1767 — quienes ocupaban la península de Baja California- y las reiteradas amenazas de otras potencias (los rusos desde Kamchatka y los ingleses desde Canadá y el Mar del Sur) los principales motivos que lo decidieron a potenciar el comercio en el Noroeste (Sonora, Sinaloa, Nayarit y California), levantar una gobernación en la península (su primer titular fue Gaspar de Portolá) y a organizar una expedición para ocupar San Diego y Monterrey, donde se levantarían sendos presidios y dos nuevas misiones a cargo de los franciscanos del colegio de San Fernando de México, quienes sustituyeron a los jesuitas en la labor de evangelizar la península. La Corona apoyó y alentó a Gálvez en estos trabajos y el virrey, a pesar de los apuros económicos, también. Sin embargo, la ausencia de buenos puertos y almacenes, la escasa presencia de pobladores españoles, y el desvanecimiento de ciertos mitos (como "el tesoro de los jesuitas" y la existencia de una flota ignaciana), provocaron numerosos contratiempos y trabajos, obstáculos que Gálvez superó con la energía de su carácter y el poder otorgado por el virrey Croix antes de salir de la ciudad de México. Su labor fue ingente, dando instrucciones y ordenanzas de todo tipo desde su llegada al fondeadero de San Blas (Nayarit), base naval elegida como punto de embarque de las tropas. Don José se ocupó de todos los aspectos: desde el nombramiento de los capitanes a las raciones de la marinería; desde reunir aparejos y pertrechos hasta la escritura de las detalladas instrucciones para los expedicionarios.

Este enorme esfuerzo no alcanzó todos sus objetivos ni fue tan rápido como se esperaba. Además de la precariedad de las misiones — diezmadas por los antiguos soldados de los jesuitas - y de la imposibilidad de realizar algunos proyectos, que quedaron en papel mojado, el visitador cayó en una profunda depresión que evolucionó hasta una enajenación transitoria. Tras varias vacilaciones, el virrey marqués de Croix ordenó su retorno a México en parihuelas ${ }^{20}$. Sin embargo, para entonces, la ambición de don José había conseguido movilizar a docenas de militares, misioneros y funcionarios que recorrieron numerosos espacios desconocidos u olvidados, haciendo posible que Carlos III extendiese sus dominios por cientos de kilómetros y que plantara su insignia en el mítico puerto de Monterrey. Aliados fundamentales fueron los franciscanos del Colegio de San

20 Río, Ignacio del: “Autoritarismo y locura en el Noroeste Novohispano. Implicaciones políticas del enloquecimiento del visitador general José de Gálvez", Estudios de Historia Novohispana, 37, 2001, México, págs. 111-138. 
Fernando de México, quienes anhelaban territorios más fértiles en tierras y hombres tras comprobar la pobreza y el abandono de muchas de las misiones jesuitas. El presidente de las misiones franciscanas, fray Junípero Serra, fue otro movilizador de voluntades y bastimentos para conseguir la conquista del norte de la California.

El visitador diseñó una doble entrada. Dos barcos saldrían desde el extremo sur de la península, el San Carlos y El Príncipe, transportando armas, víveres, objetos de culto, varios soldados, dos misioneros y sus respectivas dotaciones. El punto de reunión sería San Diego, donde llegarían por tierra otras dos partidas, que ascenderían por la península con algunas semanas de diferencia. Reunidas en el citado puerto, un grupo de hombres comenzarían la construcción de un presidio y una misión, mientras el resto de los expedicionarios seguirían hacia el norte, por mar, hasta alcanzar Monterrey, donde volverían a repetirse las fundaciones. El plan se cumplió según lo previsto (salvo que hubo que salir dos veces de San Diego para encontrar el famoso puerto de Monterrey), siendo elegido Gaspar de Portolá ${ }^{21}$ como jefe de las dos secciones. La marítima estuvo formada por dos barcos: el San Antonio y el San Carlos.

El primero, también conocido como El Príncipe, fue capitaneado por Juan Pérez, un mallorquín que había cruzado el Pacífico a bordo del galeón de Manila ${ }^{22}$. El barco partió de San Blas el 26 de octubre de 1768, poniendo rumbo a la península de Baja California, en cuyo extremo meridional ancló el 25 de enero para recibir las instrucciones de José de Gálvez. Carenado el paquebot y dotado de nuevos aparejos, el San Antonio se hizo de nuevo a la mar el 15 de febrero de 1768, realizando una amplia vuelta en el Pacífico hasta avistar el puerto de San Diego el 11 de abril de 1768. Durante el viaje, que duró cincuenta y nueve días, el paquebot sufrió fuertes balanceos, nieblas y bajas temperaturas que hicieron enfermar a numerosos tripulantes. El otro barco, el San Carlos, que había partido un mes antes que el anterior, capitaneado por Vicente Vila,

21 Gaspar de Portolá y Rovira, militar nacido en Balaguer (Lérida) en 1717 o 1718 y fallecido en Lérida en 1786, fue nombrado gobernador de California. Gálvez le encargó la expulsión de los jesuitas de la península de Baja California, trasladándose hasta allí en 1768 para realizar esta importante misión. La falta de instrucciones y la interrupción de los suministros de granos y otros bastimentos desde las misiones jesuitas de Sonora y Sinaloa llenaron de incertidumbres al nuevo jefe de California, quien tuvo que esperar la llegada del visitador general José de Gálvez para innovar en el gobierno.

22 Sobre Juan Pérez, véase Bernabéu Albert, Salvador: "Juan Pérez, navegante y descubridor de las Californias (1768-1775)", en José Luis Peset (coordinador), Culturas de la Costa Noroeste de América, Turner, Madrid, 1989, págs. 277-290. 
tuvo una travesía aún más dramática: salió un mes antes que su compañero y llegó a San Diego a finales de abril. El escorbuto y la falta de alimentos habían hecho estragos entre los expedicionarios, que se refugiaron en el interior del puerto en espera de las partidas terrestres que ascendían por la península.

La sección terrestre de la expedición se dividió en dos partes. La primera estaba mandada por Fernando de Rivera y Moncada, capitán de la Compañía de cuera de Loreto. El franciscano Juan Crespi, el pilotín José Cañizares (protagonista de nuestro trabajo), veinticinco soldados y numerosos indios de las misiones jesuitas lo acompañaban. Los expedicionarios salieron de la misión de San Fernando Velicatá el 24 de marzo de 1769 y serpentearon la península en dirección norte y noroeste. Durante las primeras jornadas, la ascensión se realizó a buen ritmo, pues varios de los soldados habían realizado el mismo camino en compañía del jesuita Wenceslao Link en 1766. Esta primera etapa del viaje terminó el primero de abril en La Cieneguilla, al pie de la sierra de San Pedro Mártir. A partir de ese punto, los expedicionarios giraron hacia el noroeste, cruzando por una árida región hasta alcanzar el valle de San Telmo. Ningún viajero había transitado por estos parajes, habitados por indios cochimíes y kiliwas (yumanos occidentales). Después siguieron ascendiendo paralelos a la costa, atravesando diversos valles y terrazas suaves que proclamaron como sedes de futuras misiones. A partir de San Vicente y hasta Ensenada, el ritmo se hizo más lento por la dificultad del terreno. Los exploradores tuvieron que ejercitarse a fondo, buscando aguajes y pasos para la recua. En la ensenada de Todos los Santos hicieron alto en la playa y, aunque el terreno mejoró, el tránsito se dificultó por la numerosa gentilidad que los acompañaba. Finalmente, el 14 de mayo alcanzaron el puerto de San Diego. Varios indios neófitos habían desertado y otros cinco fueron enterrados en el camino.

La segunda partida terrestre fue mandada por el gobernador Portolá, llevando en su compañía a fray Junípero Serra y al sargento José Francisco de Ortega. También formaban parte de la expedición varios soldados de cuera, criados e indios de las misiones, que guardaban las numerosas mulas que transportaban los víveres y otras cargas. El grupo, que había salido de Loreto el 9 de marzo de 1769, siguió los pasos de la primera partida, alcanzando el puerto de San Diego el 29 de junio. Portolá y Serra se unieron con todos los expedicionarios de tierra y mar, aunque numerosos marinos estaban postrados a causa del escorbuto. Sin embargo, decidieron que un gru- 
po prosiguiera las exploraciones para buscar el puerto de Monterrey, viaje que realizaron entre el 14 de junio y el 24 de enero de 1770. Aunque no localizaron el citado puerto, sí descubrieron el de San Francisco a finales de octubre y contactaron con numerosas rancherías de indios. La llegada de bastimentos a San Diego en el paquebot San Antonio el 23 de marzo, capitaneado por Juan Pérez, animó a Portolá a emprender nuevamente la búsqueda, esta vez por mar y por tierra. El resultado fue afortunado, tomándose posesión del puerto de Monterrey el 3 de junio de 1770. Siguiendo con las órdenes reales, se fundó un presidio y una misión bajo la advocación de San Carlos Borromeo ${ }^{23}$.

Estas expediciones dieron lugar a numerosos diarios que fueron enviados al virrey, quien mandó a España varias copias. Otros ejemplares se guardaron en el departamento de San Blas - para que sirviesen a los futuros navegantes- y en los archivos de la orden de San Francisco. También se escribieron diversas epístolas, resumiendo los preparativos y los principales acontecimientos de la jornada, y se dibujaron varios mapas de los principales puertos (La Paz, Cabo San Lucas, San Diego y Monterrey, y uno general ${ }^{24}$ ). Estos últimos serán analizados en otro trabajo, pero ahora me gustaría centrarme en los diarios de las cuatro partidas como pórtico a la edición del único que queda inédito en castellano: el firmado por el pilotín José de Cañizares. Las ediciones de los diarios de la "Santa Expedición" son:

\section{Diarios del "San Carlos", alias "El Toisón de Oro"}

El "diario de navegación" del capitán Vicente Vila está transcrito en Angela Cano Sánchez, Neus Escadell Tur y Elena Mampel González (eds.): Gaspar de Portolá. Crónicas del descubrimiento de la Alta California. 1769, Universidad de Barcelona, Barcelona, 1984, págs. 215259. En inglés fue traducido y editado por F. J. Teggart y Robert Seldon Rose (eds.): "The Portolá Expedition of 1769-1770: Diary of Vicente Vila", Publications of the Academy of Pacific Coast History, vol. 2, n. ${ }^{\circ}$, University of California, Berkeley, 1911.

23 Hilton, Silvia L.: La Alta California Española, Madrid, Mapfre, 1992.

24 Como punto de partida, véase Maximin Piette, Charles J. G., O.F.M.: "The Diarios of Early California, 1769-1784”, The Americas, vol. II, n. o 4, 1946, págs. 409-422. 


\section{Diarios del "San Antonio", alias "El Príncipe"}

No se ha encontrado el diario del capitán del barco, el mallorquín Juan Pérez, por lo que es fundamental para conocer esta navegación el del capellán fray Juan Vizcaíno: The Sea Diary of Fr. Juan Vizcaíno to Alta California, 1769, Glenn Dawson, Los Angeles, 1959. Fue editado en castellano por Salvador Bernabéu Albert: "La Santa Expedición en el mar. El diario de fray Juan González Vizcaíno (1769)”, en Castilla y León en América, Junta de Castilla y León, Valladolid, 1992, vol. III, págs. 59-77.

\section{Diarios de la primera partida terrestre}

La primera partida terrestre fue comandada por el capitán Fernando Javier Ribera y Moncada. No se conserva el diario, por lo que es fundamental el escrito por el misionero fray Juan Crespi. Fue publicado por Maynard J. Geiger: "The Arrival of the Franciscans in the Californias, 1768-1769, according to the version of Fray Juan Crespi, O.F.M.", The Americas, vol. VIII (Oct., 1951), págs. 209-218. Para conocer los diferentes diarios de este misionero, véase Alan K. Brown: "The various Journals of Juan Crespi”, The Americas, vol. XXI (April, 1965), págs. 375-398. El diario de Crespi se incluyó en la obra: Fray Francisco Palóu's Historical Memoirs of New California, editado por Herbert Eugene Bolton (University of California Press, 1926, 2 vols.). En castellano, existen dos ediciones recientes. Fray Salustiano Vicedo la transcribió en: El mallorquín fray Juan Crespi, O.F.M. Misionero y explorador. Sus diarios, Unión Misional Franciscana, Valencia, 1994, pp. 133-173. Carlos Lazcano Sahagún firma la segunda, acompañada de notas geográficas y botánicas de gran interés, en: La primera entrada. Descubrimiento del interior de la Antigua California, Ensenada, Fundación Barca-Museo de Historia de Ensenada-Seminario de Historia de Baja California, 2000, págs. 226-294. Lazcano ha seguido la edición del diario de Crespi que se encuentra en la obra de fray Francisco Palóu: Recopilación de la Antigua y de la Nueva California (1767-1783), edición de José Luis Soto Pérez e introducción de Lino Gómez Canedo, Editorial Porrúa, México, 1998, págs. 265-317.

Otra importante fuente de este viaje es el diario de José Cañizares, que fue traducido al inglés por Virginia E. Thickens y Margaret Mollins y publicado en: "Putting a Lid on California: An Unpublished Diary of the 
Portolá Expedition by José de Cañizares", California Historical Society Quarterly, vol. 31, n. ${ }^{\circ} 2$ (June, 1952), págs. 109-123; n. 3 (Sept., 1952), págs. 261-270; y n. ${ }^{\circ} 4$ (Dec., 1952), págs. 343-354. La edición en castellano acompaña a esta introducción.

\section{Diarios de la segunda partida terrestre}

El diario del gobernador Gaspar de Portolá, que se conserva en la Biblioteca Nacional de Madrid ha sido transcrito en Noticias y Documentos acerca de las Californias, 1764-1795, Madrid, José Porrúa Turanzas, 1959, págs. 49-76 ("Diario del viaje que hace por tierra D. Gaspar de Portolá, a los puertos de San Diego y Monterrey en las Californias"). De los dos misioneros que le acompañaron, fray Miguel Campa y fray Junípero Serra, sólo se conserva el diario del segundo. El texto de Serra, que era presidente de las misiones, fue publicado en inglés por Charles Fletcher Lummis en la revista Out West, vols. XVI (March, 1902), págs. 293-296; (April, 1902), págs. 399-406; (May, 1902), págs. 513-518; (June, 1902), págs. 635-642; y (July, 1902), págs. 69-76. Otras dos ediciones en inglés fueron publicadas por las Franciscanas Misioneras de María, de North Providence (R. I.) en el año 1936, y por Benjamin Franklin Dixon: Journal of Padre Serra from Loreto ... to San Diego, Don Diego's Librería, San Diego, 1964. En edición bilingüe inglés-español, se incluyó en el primer volumen de los Writings of Junipero Serra (Washington, Academy of American Franciscan History, 1955, págs 38-122). La transcripción en castellano fue realizada por Lino Gómez Canedo, quien la editó junto a otros documentos en: De México a la Alta California. Una Gran Epopeya Misional, Editorial Jus, México, 1969, págs. 17-69. Más modernas son las transcripciones en los Escritos de fray Junípero Serra, preparada por fray Salustiano Vicedo (Apóstol y Civilizador, Petra, 1984, vol. I) y la reciente de Carlos Lazcano (introducción y notas): Diario de fray Junípero Serra de su caminata de Loreto a San Diego, Provincia Franciscana de San Pedro y San Pablo de Michoacán - Gobierno del Estado de Baja California-, Fundación Barca, Ensenada, 2002.

El diario fue utilizado por fray Francisco Palou en su Relación Histórica de la vida y apostólicas tareas del venerable padre Fray Junípero Serra, México, Imprenta de don Felipe de Zúñiga y Ontiveros, 1787 (edición moderna con estudio preliminar de Miguel León-Portilla en Editorial 
Porrúa, México, 1982); y en el obra (manuscrita): Recopilación de la Antigua y de la Nueva California (1767-1783), edición de José Luis Soto Pérez e introducción de Lino Gómez Canedo, Editorial Porrúa, México, 1998, págs. 318-363.

DE VELICATÁ A SAN DIEGO. LA RUTA DE JOSÉ DE CAÑIZARES, 1769

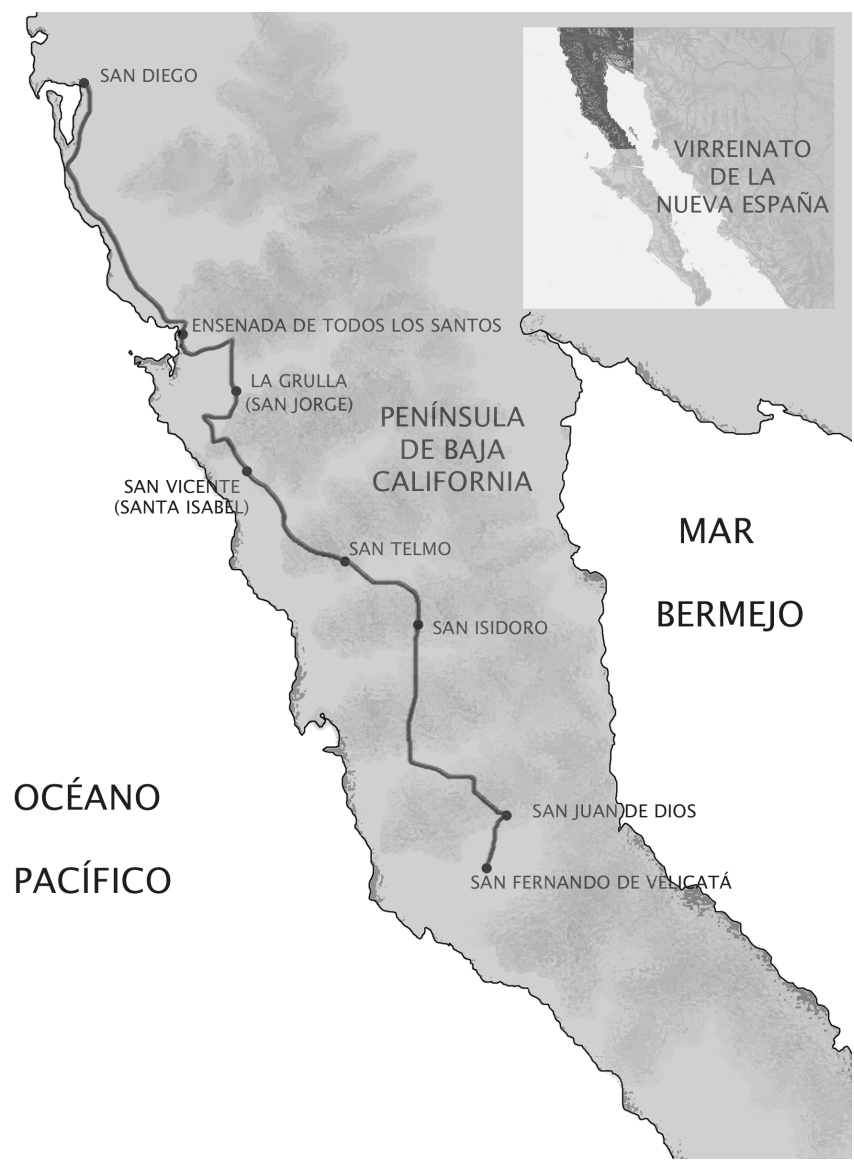

\section{El diario de Cañizares}

El texto del diario está encabezado con el título: "Diario de Joseph de Cañizares, Villacatá a San Diego, julio 3, 1769". Se inicia el 24 de marzo de 1769 y termina el 14 de mayo. Solo se conoce una copia, que se guarda 
en el Archivo General de Indias (Guadalajara, 417). Un ejemplar en microfilm se guarda en la Bancroft Library (University of California, Berkeley); sirvió de base para la edición de Virginia E. Thickens y Margaret Mollins. La edición que acompaña a esta introducción es la primera que se realiza en español, la lengua original del texto. He actualizado la ortografía y la puntuación, desarrollando las abreviaturas y reduciendo las mayúsculas a las precisas. Todos estas modificaciones han tenido como fin facilitar la lectura del texto. Entre corchetes incluyo algunas palabras añadidas y he redactado varias notas para aclarar las platas, animales, personas, lugares y términos que salpican el texto.

Como he señalado anteriormente, el diario de José de Cañizares viene a completar las ediciones en castellano de los relatos de viaje de la "Santa Expedición". Sus aportaciones servirán para completar las noticias que escribió fray Juan Crespi sobre los sucesos de la expedición, sobretodo en los últimos días de la misma, en la que recorrieron los parajes donde se levantaron posteriormente las ciudades de Ensenada y Tijuana. Pero, además, el texto de Cañizares tiene una diferencia notable con aquél. Pues mientras el franciscano escribió su diario con posterioridad, sirviéndose de sus apuntes y del diario escrito por fray Junípero Serra, que le siguió los pasos con la segunda expedición de tierra, nuestro marino ofrece un relato inmediato a los acontecimientos menos interesado en buscar indios que convertir. Como señaló Antonello Gerbi, los crónicas no coinciden en sus lenguajes: "Diversos son sus intereses mentales, y diverso, en consecuencia, el ángulo visual desde el cual contemplan el mundo americano" 25 . Sirvan estas palabras para introducir la lectura de este texto que, tras "haberse confundido con otros papeles" fue enviado por el virrey marqués de Croix al secretario de Indias Julián de Arriaga el 27 de julio de $1770^{26}$.

25 Gerbi, Antonello: La naturaleza de las Indias Nuevas. De Cristóbal Colón a Gonzalo Fernández de Oviedo, Fondo de Cultura Económica, México, 1975, pág. 149. Sobre la necesidad de estudiar todos los textos de los viajeros, véase Bernabéu Albert, Salvador: “illusos o ilustrados? Novedades y pervivencias en los viajes del setecientos", Revista de Occidente, n. ${ }^{\circ}$ 260, Madrid, 2003, págs. 36-55.

26 El texto de la carta del marqués de Croix es el siguiente: "Muy señor mío. Paso a manos de vuestra excelencia el diario de viaje ejecutado por tierra desde Vilacatá hasta el puerto de San Diego, a fin que, instruido vuestra excelencia de su contenido, se sirva mandarlo agregar al que remití en carta de 4 de mayo último, con que no lo acompañé por haberse confundido entre otros papeles. Nuestro Señor guarde a vuestra excelencia muchos años. México, 27 de julio de 1770”. AGI, Guadalajara, 417. 


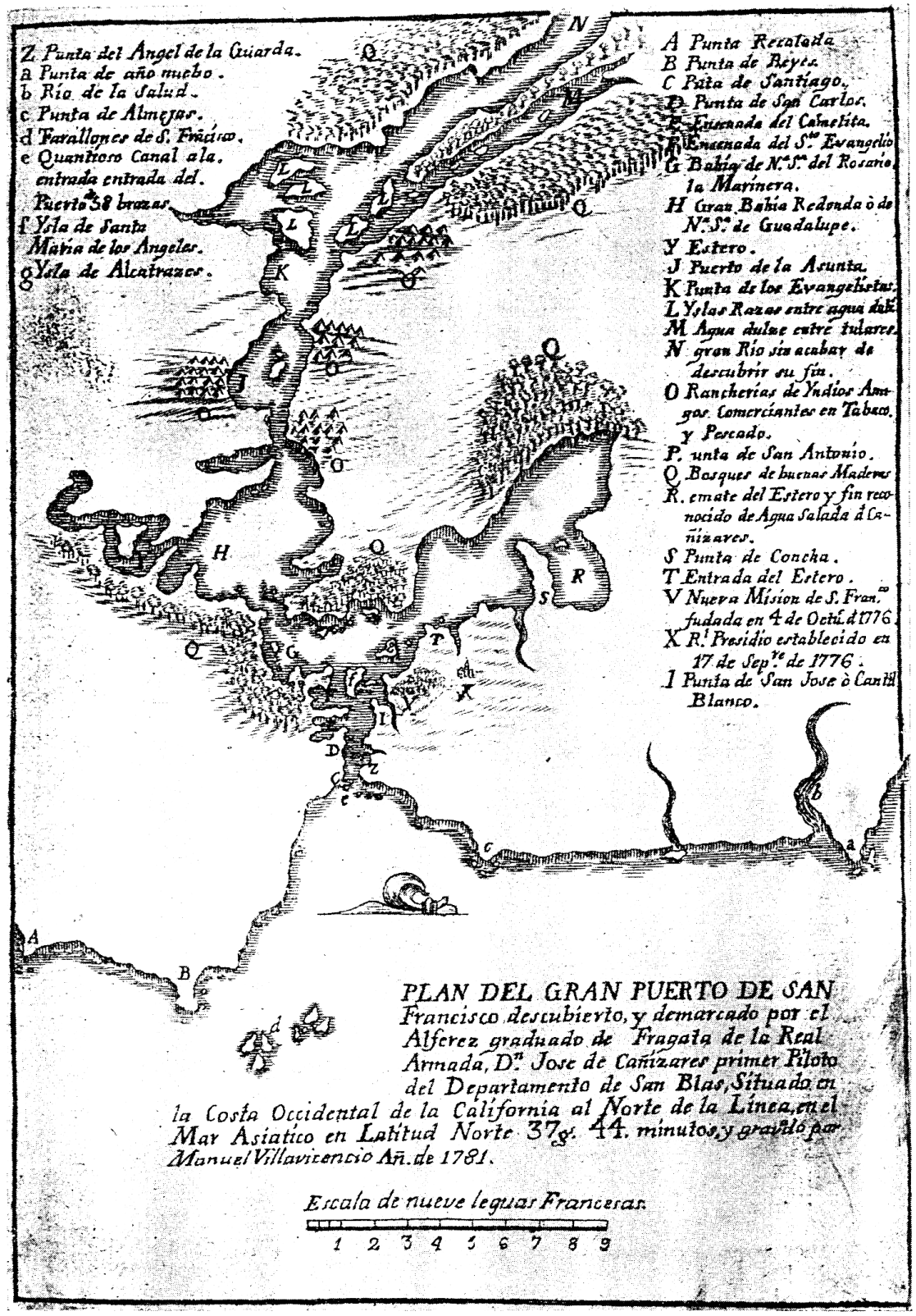

José de Cañizares: Plano del gran puerto de San Francisco (1781). 


\section{Apéndice}

\section{DIARIO DE JOSÉ DE CAÑIZARES (1769)27}

Copia del diario ejecutado por tierra desde el paraje de Vilacatá ${ }^{28}$ a este puerto de San Diego ${ }^{29}$, situados por los 30 grados, 20 minutos el primero, y el segundo en los 32 grados, 44 minutos de latitud, comprendidos en la península de Californias.

Día 24 de marzo del año de 1769. A las cuatro de la tarde, habiendo juntado los soldados, dio orden el capitán don Fernando de Ribera ${ }^{30}$ para que se cargara

27 Para completar el diario de Cañizares, recupero en notas la información proporcionada por fray Juan Crespi. Además, he adjuntado los topónimos con los que fray Junípero Serra rebautizó los diversos parajes. Las referencias pertenecen a las transcripciones de los diarios que se encuentran en la obra de fray Francisco Palou (editada por José Luis Soto Pérez): Recopilación de noticias de la Antigua y de la Nueva California (1767-1783), Editorial Porrúa, México, 1998, 2 tomos. El diario de fray Juan Crespi ocupa las páginas 265-317 del primer tomo, y el de fray Junípero Serra, de la 318 a la 363 del mismo.

28 En el título original: "Villa-cata", si bien Cañizares escribe en otras tres ocasiones a lo largo del diario: "Villacatta". El paraje fue explorado por el jesuita Wenceslao Link en 1766 y visitado por el capitán Fernando de Rivera y Moncada el 20 de diciembre de 1768. El sitio, situado a setenta y tres kilómetros al noroeste de la misión de Santa María de los Ángeles, última fundación de la Compañía de Jesús (1767), fue elegido por Serra como base para la expedición a la Alta California. Sobre esta misión, véase Adalberto Walther Meade: "San Fernando de Velicatá, apoyo

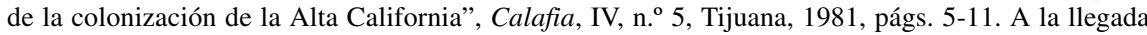
de la segunda expedición terrestre, fray Junípero Serra fundó formalmente la misión de San Fernando Rey de España de Velicatá el 14 de mayo de 1769, nombrando al padre Miguel Campa y Cos como misionero residente. Esta fue la única misión levantada por la Orden de San Francisco en la península de Baja California, siendo abandonada en 1818 por falta de neófitos, pero ya durante el periodo dominico. Fray Juan Crespi señaló en su diario: "No pude observar por estar siempre nublado, pero don José Cañizares me dijo que había observado este paraje en la latitud del norte 30 grados y 36 minutos" (Palou: Recopilación de noticias..., I, pág. 277). En realidad se encuentra en los $29^{\circ} 58^{\prime} 14^{\prime \prime} \mathrm{N}$, diferencia de más de medio grado que se mantendrá durante todo el viaje, lo que demuestra que ni Cañizares ni Crespi eran buenos medidores o que le faltaron los instrumentos necesarios.

29 El puerto de San Diego fue descubierto por Juan Rodríguez Cabrillo en 1543, bautizándolo como San Miguel. Sebastián Vizcaíno lo exploró el 10 de noviembre de 1602. Este último le puso el definitivo nombre de San Diego y describió las cualidades naturales y la abundancia de agua. Sobre esta expedición, véase Mathes, W. Michael: Sebastián Vizcaíno y la expansión española en el océano Pacífico, 1580-1630, UNAM, México, 1973, pág. 65.

30 Nacido en Compostela (Nayarit) en 1725, Fernando de Ribera y Moncada fue comandante del presidio de Loreto entre 1750 y 1767, año de la expulsión de los jesuitas, con varios de los cuales había explorado numerosos parajes del centro y norte de la Baja California. Sus cualidades de magnífico explorador se pusieron de manifiesto - una vez más- durante la "santa expedición", que logró abrir el camino real entre San Fernando Velicatá y San Diego. Más tarde volvería a protagonizar otras explo- 
y, estándose aparejando, se apartaron los víveres y demás pertrechos necesarios. A las cuatro y media, aprontado todo, salimos ejecutando el rumbo del nornordeste y, habiendo caminado como legua y media, hicimos alto, parando el real en un arroyo $\operatorname{seco}^{31}$. Aquí distribuyó el capitán sus órdenes para el día venidero a los soldados, repartiéndolos en resguardo de la recua y custodia de la caballada; yendo en su compañía, la del padre ${ }^{32}$ y mía diez soldados que servían de exploradores ${ }^{33}$. Quedamos sin novedad. A las avesmarías se pusieron en el real dos centinelas de posta y tres en la caballada. Éstas se remudan durante la noche.

Día 25. De la mañana se arrimó la caballada, empezamos a cargar y, listos todos, salimos por entre cerros siguiendo el curso del arroyo. A las siete y media dirigimos nuestro camino al nornordeste. Habiendo avanzado como dos leguas, entramos en tierra llana y apacible. A las doce y media llegamos sin haber variado el rumbo al arroyo de San Juan de Dios (reconocido por los padres jesuitas ${ }^{34}$ en la última entrada que hicieron), que estaba bien empastado, hallándose el agua en pozas y por sus orillas abastecidas de unos árboles llamados sauces. En esta jornada ha seguido la esterilidad de la tierra por estar sembrada de abrojos y espinas, teniendo algunas palmas y palos llamados ci-

raciones en ambas Californias, muriendo en una emboscada en el río Colorado en 1781. Fue nombrado gobernador de California entre 1774 y 1777. Sobre el personaje, véase Burrus, Ernest (editor): Diario del capitán comandante Fernando de Rivera y Moncada, José Porrúa Turanzas, Madrid, 1967; y Crosby, Harry W.: Antigua California. Mission and Colony on the Peninsular Frontier, 1697-1768, University of New Mexico Press, Alburquerque, 1994, págs. 333-350.

31 Los expedicionarios se detuvieron en el arroyo de los Torotes, en el valle de las Ánimas.

32 Fray Juan Crespi nació en Mallorca en 1721. Entró en la orden franciscana y en 1749 se trasladó a la Nueva España. Fue misionero en la Sierra Gorda (Querétano) antes de trasladarse a la península de California en compañía de su paisano fray Junípero Serra. Participó en varias expediciones por mar y por tierra, que narró en excelentes diarios, considerados como fuentes imprescindibles para el estudio de la expansión española en el Noroeste de la Nueva España. Murió en la misión del Carmelo (Monterrey) el 1 de enero de 1782. Sobre su biografía, véase Geiger, Maynard, O.F.M.: Franciscan Missionaries in Hispanic California, 1769-1848, The Huntington Library, San Marino, 1969, págs. 51-55; y Vicedo, Salustiano, O.F.M.: El mallorquín fray Juan Crespi, O.F.M. Misionero y explorador. Sus diarios, Unión Misional Franciscana, Valencia, 1994

33 Según Crespi, la expedición se componía del capitán Rivera, el pilotín José de Cañizares, veinticinco soldados de cuera, tres arrieros y cuarenta y dos indios cristianos de las misiones del norte de la península. Varios de estos indios desertaron durante los primeros días o fueron enviados de vuelta por enfermedad. Palou: Recopilación de noticias..., I, pág. 277. El franciscano apuntó en el diario que Cañizares iba por orden del visitador general: "para formar su Diario y observar" (pág. 277).

34 El arroyo fue descubierto y bautizado por el jesuita Wenceslao Link el 7 de marzo de 1766: "Todo el paraje, parece se fabricó para estancia de ganado; sombra, agua, pasto, campo espacioso en que sin remontarse el ganado se extienda, lo hacen sitio oportuno para mantener el ganado mayor, bastante para el abasto de una misión, y las demás bestias a sus excursiones y faenas. Se llamó este paraje San Juan de Dios". Véase, Link, Wenceslao: "Diario del viage que se hizo en la provincia de California al Norte de esta península por febrero de este año de 1766", en Lazcano, Carlos: La primera entrada. Descubrimiento del interior de la Antigua California, Fundación Barca-Museo de Historia de Ensenada-Seminario de Historia de Baja California, Ensenada, 2000, págs. 206. 
rios $^{35}$ y cardones ${ }^{36}$, de que sacan los indios sus semillas. De las palmas sacan el dátil cimarrón ${ }^{37}$ y del cardón unas pepitas con las cuales, el mescal ${ }^{38}$ y la pesca se mantienen. Vimos algunos animales, como son liebres ${ }^{39}$ y cabras ${ }^{40}$ de hermosa vista, pero corren como tienen el nombre. Vinieron al real unos gentiles, a los que se les dio sus abalorios ${ }^{41}$. Regulo desde Vilacatá a este paraje siete leguas. Quedamos sin novedad alguna y anochecimos dando las mismas disposiciones el capitán que la noche pasada. (Al margen: 7 leguas)

Día 26. De mañana se dijo la santa misa y como a las ocho nos avisaron de que un indio cristiano ${ }^{42}$ estaba muy malo. Fue el padre a verlo y juntamente a hacer diligencia de confesarlo y, no pudiendo conseguirlo, lo absolvió bajo de condición. A las once expiró. Esto y el haber encontrado suficiente pasto para que la caballada descanse, nos movió a no salir hasta las tres de la tarde que, estando prontos, caminamos sobre el rumbo del noroeste cuarta al oeste, declinando para el oes-nor-

35 El cirio (Idria columnaris) fue descrito por el jesuita croata Fernando Consag en el diario de la expedición de 1751 al norte de la Baja California. El misionero escribió: "Hacia los 29 grados se comienza a ver un árbol de que no se halla semejante en toda la California cristiana, desde el Cabo de San Lucas hasta la dicha altura, ni aun sabemos que en toda la Nueva España, ni en otra parte del mundo se halle tal especie de árbol. De los cuales hay grande abundancia en los territorios en que se fundó la misión de San Borja". Véase Lazcano, Carlos, y Pericic, Denis: Fernando Consag. Textos y Testimonios, Fundación Barca-Municipalidad de Varazdín-Museo de Historia de Ensenada-Seminario de Historia de Baja California, Ensenada, 2001, págs. 285.

36 El cardón (Pachycereus pringlei) es una planta cactácea de gran altura que abunda en toda la península. Se puede encontrar una interesante descripción en la obra del jesuita Miguel del Barco: Historia natural y crónica de la Antigua California, edición y estudio de Miguel León-Portilla, Universidad Nacional Autónoma de México, México, 1988, págs. 83-86. Véase, asimismo, los comentarios del también jesuita Fernando Consag (Lazcano y Pericic: Fernando Consag ..., págs. 334-335).

37 En el norte de la península de California se encuentran varias clases de palmas, destacando la Washingtonia filifera y la palma blanca o Washingtonia robusta, que llega a alcanzar los treinta metros. También abunda la palma azul o ceniza (Erythea armata). Sin embargo, el dátil cimarrón probablemente sea la Yucca schidigera, cuyo fruto en racimos se parece a los dátiles.

38 El mezcal, término que engloba diversas especies de agaves, era fundamental en la dieta indígena. El jesuita Miguel del Barco señaló que: "exceptuando los playanos, que toman del mar su principal sustento, los demás no pudieran vivir si no hubiera mezcal”. Barco: Historia Natural ..., pág. 121.

39 La liebre que se encuentra en California es la Lepus californicus, también conocida como liebre de cola negra. Tanto las liebres como los conejos eran muy demandados por los indígenas, quienes, además, utilizaban sus pieles para vestidos y bolsas.

40 Los jesuitas llamaban cabra montés al berrendo peninsular (Antilocarpa americana peninsularis). Véase, el trabajo de González Romero et al.: "El berrendo peninsular", en Ortega, Alfredo, y Arriaga, Laura (editores): La reserva de la biosfera el Vizcaíno en la península de Baja California, Centro de Investigaciones Biológicas de Baja California Sur, La Paz, 1991, págs. 295-311.

41 Según fray Juan Crespi: "Al llegar a este arroyo había una buena ranchería de gentiles, que así que nos sintieron se corrieron todos, pero nuestros indios se adelantaron y trajeron a un gentil todavía mozo, todo desnudo, y muy rayado; y un soldado le dio un cigarro encendido, y lo chupó con mucho garbo". Palou: Recopilación de noticias ..., I, pág. 278. Los indios pertenecían al grupo cochimí, uno de los principales de la península, que habitaba entre los paralelos 26 y 30

42 Se trataba de un indio de la misión de Santa Gertrudis (Baja California) llamado Rafael. Fue enterrado y se puso una cruz para recordar el sitio. 
oeste y, habiendo avanzado como tres leguas de tierra llana, llegamos a las seis y media a un arroyo llamado de los Mártires ${ }^{43}$, en el que se halla el agua en pozas y abundancia de pastos. En el camino vimos algunas liebres y rastro de leones ${ }^{44}$ en unos cerros que distarán de San Juan de Dios una legua y media (por los rumbos que ejecutamos). Según dicen los inteligentes, parecían ser de ricos minerales; lo cierto es que tenían hermosa vista. La esterilidad de la tierra continúa en la misma forma que la jornada de ayer. El capitán distribuyó su gente para el real y caballada. Quedamos sin novedad alguna. (Al margen: 3 leguas)

Día 27. De mañana se celebró el santo sacrificio de la misa y como a las siete nos empezaron a caer fuertes aguaceros de agua que duraron hasta las dos de la tarde, en cuya hora mandó el capitán se aparejara para seguir nuestro camino, lo que ejecutamos a las dos y media por el rumbo del oes-sudoeste siguiendo el curso del arroyo. Como a las cuatro de la tarde empezó a llover con la misma violencia de la mañana y, habiendo caminado como dos leguas, nos vimos precisados a hacer mansión por continuar el agua. A las seis de la tarde paramos el real en el expresado arroyo de los Mártires, el cual tiene algunas leguas de largo, siguiendo su curso para la costa occidental de esta península. El agua se halla en pozas y por sus inmediaciones bastantes pastos. Sigue la esterilidad de la tierra. Quedamos sin novedad alguna. El capitán dispuso su gente como la noche anterior. (Al margen: 2 leguas)

Día 28. De mañana se celebró la santa misa y no salimos por estar siguiendo el agua. Avisaron que dos indios cristianos estaban muy malos, a los que asistió el padre dándoles la santa extremaunción ${ }^{45}$. Esto nos fue causa para que no saliéramos de parte de tarde por estar los enfermos de mucho cuidado, en el que quedamos y sin otra novedad, a Dios gracias.

Día 29. A las cinco de la mañana avisaron había muerto un indio ${ }^{46}$ de los dos que se habían oleado ayer y que habían enfermado tres. Esto obligó al capitán a entrar en alguna sospecha, por lo que mandó juntar a todos los indios y los estuvo exhortando a fin de que siguieran a una expedición tan santa como a la que íbamos y que no presumieran que los dos que habían muerto era por seguir nuestra empresa. Habiéndolos estado interpretando, dejamos a los enfermos para que de allí se retiraran a Vilacatá, haciéndose cargo el capitán de lo próximo que estaba la misión de 1766.

43 El arroyo de los Mártires fue descubierto por el jesuita Wenceslao Link el 10 de marzo

44 Los supuestos leones eran en realidad pumas (Felis concolor), como indica el jesuita Miguel del Barco en su crónica: "Hay también muchos leopardos, que son los que en el reino de México vulgarmente llaman leones, y los californios en lengua cochimí, llaman chimbiká, que significa gato montés grande". Véase, Barco: Historia natural ..., pág. 17.

45 Según el padre Crespi, siete indios enfermaron en este paraje. Todos ellos fueron confesados y, a dos que se encontraban más graves, se les dieron los santos óleos. Palou: Recopilación de noticias..., I, pág. 280 .

46 El indio fallecido se llamaba Luis y pertenecía a la misión de San Ignacio Kadakaamán (Baja California). Estaba casado con otra india llamada Mónica. Fue enterrado y se colocó una cruz. 
frontera $^{47}$. A las diez y tres cuartos salimos de este paraje por el rumbo del oesnoroeste. A las once y media dejamos este arroyo, tomando una subida que seguía por el referido rumbo, llegando sin variarlo a las tres de la tarde al arroyo de las Palmas, tomado este nombre por los padres jesuitas ${ }^{48}$. Este arroyo está con algunos sauces. El agua no la habemos encontrado, por lo que hicimos mansión a las tres y media a orillas del arroyo, de donde se mandaron cuatro soldados para que buscaran agua. Éstos llegaron como a las oraciones y dieron noticia [de] que una legua distante de nosotros (siguiendo el curso del arroyo para la parte occidental) había un ojo de agua muy buena y que todas sus inmediaciones eran de tierra de siembra, con bastante pasto y abundancia de sauces, pero que el agua a poco se sumergía en la arena. Por lo distante que estaba el agua y el ver que la jornada de mañana no la tenía, dispuso el capitán de no salir de este paraje hasta mañana a la tarde para que beba agua la caballada.

Los enfermos que habíamos dejado en el arroyo de los Mártires llegaron tres a este paraje y dijeron que, luego que salimos, habían bajado diez gentiles y que el miedo les había hecho venir a donde estábamos, y que los otros dos habían seguido para Vilacatá ${ }^{49}$. Regulo desde los Mártires a aquí tres leguas. Quedamos sin novedad y el capitán distribuyó sus órdenes como la noche anterior. (Al margen: 3 leguas)

Día 30. Amanecimos sin novedad alguna, aunque con una neblina sumamente grande. Al mediodía tomé la altura de este paraje, la que observé de 30 grados, 50 minutos $^{50}$. A las doce y media nos empezamos a aprontar, y a la una y media salimos de este paraje dirigiendo nuestro camino al norte $\mathrm{y}$, por los rodeos que nos hacían dar los cerros, declinábamos para el nordeste. A las cinco y media de la tarde llegamos a un paraje llamado el Alamillo de la Tinaja ${ }^{51}$, sin agua, sólo con algunas pozas. Todo el camino fue bien molesto por los muchos barrancos de que se componía, siguiendo la esterilidad de la tierra con muchos

47 Según fray Juan Crespi: "Al otro indio que también está muy malo, se dispone lo carguen los buenos en tapestle; y los cinco que no están tan malos dispone el comandante que se vuelvan a sus misiones, con dos o tres de los buenos que los acompañen”. Palou: Recopilación de noticias ..., I, pág. 280 .

48 Carlos Lazcano lo identifica con el arroyo del Potrero, al sur del rancho San Antonio (Lazcano: La primera entrada ..., pág. 250, nota 47). El padre Junípero Serra lo bautizó con el nombre de Santiago, pues llegaron el 23 de mayo, día en el que se conmemora: "su aparición en ayuda de los españoles". Palou: Recopilación de noticias ..., I, pág. 335.

49 Coincide con la versión de fray Juan Crespi: “y dieron razón cómo luego de salidos nosotros del arroyo de los Mártires, les salieron diez gentiles muy armados, y de miedo se animaron a seguirnos, y parece se van aliviando los pobres”. Palou: Recopilación de noticias ..., I, pág. 281. Este franciscano añade otro dato interesante: la huida de nueve indios que los acompañaban, cuatro de la misión de Santa Gertrudis y cinco de la de San Francisco de Borja.

50 Fray Juan Crespi coincide con esta medición: "Tomé la altura del norte en este paraje, y me salió su latitud de 30 grados y 50 minutos”. Palou: Recopilación de noticias ..., I, pág. 281.

51 El padre Crespi lo bautizó arroyo de la beata Ángela de Fulgino; y fray Junípero Serra, de Corpus Christi. Palou: Recopilación de noticias ..., I, pág. 335. Ninguno de esos nombres prosperó, siendo conocido como arroyo de los Álamos, al pie de la sierra de San Miguel, en el extremo sur de la sierra de San Pedro Mártir. 
abrojos $^{52}$ y chollas ${ }^{53}$. Mandó el capitán a cuatro soldados para ver si en el sitio que llaman La Tinaja había agua. Estos vinieron y dieron noticia que había, pero que a poco se sumergía. A las oraciones llegaron a este paraje dos gentiles: una mujer y el otro anciano, a quienes se les dieron unos abalorios. Aquí usan las indias alguna más honestidad que las que dejamos atrás, por vestir éstas sus partes honestamente con una especie de sartillas de carrizo que les servían de [e]naguas y con pellejos de varios animales formaban las mantas con que se cubren los pechos ${ }^{54}$. Regulo desde el arroyo de las Palmas a este paraje tres leguas. Quedamos sin novedad alguna, dando el capitán sus disposiciones como la noche pasada. (Al margen: 3 leguas)

Día 31. Al amanecer se juntó la caballada y a las siete y media salimos de este paraje dirigiendo nuestro camino al norte, declinando para el noroeste. A las once llegamos al arroyo de los Álamos, cuyo nombre se lo dieron en la última entrada por los muchos árboles de esta especie que le adornan. Luego que salimos, empezamos a subir cuestas y, en un llano próximo a donde salimos, avistamos una ranchería sin gente con once casas fabricadas al modo de chozas. Habiendo caminado como dos leguas, vimos una lumbrada y que por los cerros corrían gentiles. Esto obligó al capitán a mandar cuatro soldados por ellos, los que trajeron tres párvulos y una vieja, a los que se les dieron sus abalorios. Los indios cristianos tomaron el cerro por donde corrían los otros y, estando en la cumbre, divisaron diez. Siguieron en su demanda y, habiéndolos alcanzado, les regalaron cuatro tercios de mescal para el padre ${ }^{55}$. Por el camino se vieron algunos sitios bien empastados pero sin agua. En esta jornada se empieza a esparcir la tierra, vistiéndose de unos árboles llamados juníperos ${ }^{56} \mathrm{y}_{\text {enebros }}{ }^{57}$, y, por lo que parece, ya nos dejaron los abrojos.

52 El abrojo es una planta de la familia de las cigofiláceas, de tallo largo y rastrero, armada de fuertes púas.

53 La cholla (Opuntia cholla) era una planta con mala fama porque dificultaba el tránsito de los caminantes debido a sus numerosos pinchos. El jesuita Miguel del Barco la calificó de planta "inútil y dañosa". Barco: Historia natural ..., pág. 92.

54 Fray Juan Crespi añade algún detalle a este encuentro: "el gentil andaba todo desnudo, como andan todos los demás, la muchacha andaba honestamente tapada con unos hilos tupidos por delante, y por detrás desde la cintura con unos cueros de venado. El señor comandante le dio a la muchacha unos abalorios y zarcillos de vidrio, y por señas le dijo que se los colgara, y luego con mucho garbo se los colgó de las orejas”. Palou: Recopilación de noticias ..., I, pág. 281.

55 Añade fray Juan Crespi: "Así que hubimos llegado nuestros neófitos nos trajeron cuatro envoltorios, que eran cuatro panes grandes de mezcales tatemados molidos, que me entregaron dándome razón que en el cerro se habían encontrado a una docena de gentiles, que se los habían dado para el padre, y que ellos vendrían a verme por la mañana, los que nunca se dejaron ver. Repartí tres de los panes a nuestros neófitos, y el otro sirvió para que lo gustáramos el señor comandante, algunos soldados, y yo, y confieso que es conserva muy deliciosa y dulce; y este es el pan cotidiano de los miserables gentiles, y de todos nuestros neófitos, en particular los del rumbo del norte de la California, que son los más pobres". Palou: Recopilación de noticias ..., I, pág. 282.

56 Se trata de la Juniperus californica, una variedad de cipreses también conocido como huata o táscate en otras regiones de México.

57 Fray Juan Crespi lo contradice: "pensé si serían enebros, y vi no lo eran mirándolos con más refleja". Palou: Recopilación de noticias ..., I, págs. 281-282. 
La vista de este arroyo de los Alamos es hermosa por lo muy vestido que están sus orillas de estos árboles. Es sitio deleitable para caza por encontrarse conejos y cabras de hermosa pinta, algunas aves y venados ${ }^{58}$, pero entre todas estas frondosidades le falta lo mejor, que es el agua, pues, para que bebiese la caballada, fue preciso abrir un batequi ${ }^{59}$. Habrá desde el Alamillo de la Tinaja a este paraje tres leguas. (Al margen: 3 leguas)

Día 1. ${ }^{\circ}$ de Abril. A las siete y media de la mañana salimos de este arroyo de los Alamos caminando al norte directo. Se adelantó el capitán con diez soldados para ver si en el venidero paraje había algunos gentiles. Todo el camino lo hicimos de tierra llana y a las doce y media llegamos a un paraje llamado La Cieneguilla (último término de la entrada que hicieron los padres jesuitas ${ }^{60}$ ), en donde hicimos alto por estar el capitán esperándonos y ser el sitio bien empastado. Regulo desde los Alamos a este paraje el agua se halla en ciénega. Quedamos sin novedad, observando las órdenes que distribuye el capitán de parte de noche con sus soldados.

Día 2. De mañana salieron seis soldados exploradores para ver si podían coger unos gentiles que nos dirigieran al aguaje para seguir nuestro camino, los que llegaron a las nueve del día y trajeron tres indios gentiles. A uno de ellos se despachó, dándole abalorios, para que avisara a su gente cómo íbamos nosotros y que no presumiesen hacíamos daño. No pudimos salir este día por haber enfermado la noche pasada un soldado y estar de bastante cuidado ${ }^{61}$. Quedamos lo restante del día sin novedad, más que una neblina que me ha impedido tomar la altura de este paraje $\mathrm{e}^{62}$.

Día 3. A las nueve y tres cuartos de la mañana salimos con la noticia que nos daban los gentiles de esta ciénega por la falda de la Sierra Madre, ejecutando el rumbo del nornoroeste, declinando para el noroeste. A las dos de la tarde llegamos a un arroyo, que se dedicó a san Ricardo ${ }^{63}$, en donde paramos el real con bastante incomodidad por lo muy encajonado que era el arroyo. Por el camino vimos tres

58 Se trata del venado bura (Odocoileus hemionus). Véase, Mellink, Erik; Luévano, Jaime y Domínguez, Jorge: Mamíferos de la península de Baja California, Centro de Investigación Científica y de Educación Superior de Ensenada, Ensenada, 1999, pág. 112.

59 Batequi: pozo excavado en el suelo.

60 La expedición siguió la ruta del jesuita Wenceslao Link en 1766. Fray Juan Crepi añade: "como lo aseguran muchos soldados que acompañaron al padre y ahora vienen en esta expedición, y de aquí habremos de tomar otro rumbo, para la contracosta". Palou: Recopilación de noticias ..., I, pág. 283. En la actualidad, el paraje está ocupado por un rancho llamado La Rinconada, que da nombre al valle, situado a los pies de la Sierra de San Pedro Mártir, que fue conocida durante algún tiempo como sierra de la Cieneguilla.

61 Según fray Juan Crespi, esta noche se enfermó el soldado Guillermo Carrillo y un indio, elevándose a tres los miembros de la expedición que tuvieron que ser transportados en tapestle. Palou: Recopilación de noticias ..., I, pág. 283.

62 Sí la tomó fray Juan Crespi: 30 56’ N, siendo en realidad de 30³4' 07’' (Lazcano: La primera entrada..., pág. 255, nota 55)

63 En la actualidad se conoce como arroyo del Alamoso. Está situado al noroeste del valle de San José, que atravesaron los expedicionarios en esta jornada. El padre Junípero Serra recomendaría el sitio para una misión, que dedicó a Santa Humiliana. Palou: Recopilación de noticias ..., I, pág. 338. 
aguajes abundantes de pastos y abastecidos de árboles llamados pinos, álamos, sauces, alisos y juníperos, y, según dicen los inteligentes, parecían tener algunos cerros indicios de ricos minerales. Regulo desde La Cieneguilla a este arroyo de San Ricardo tres leguas y media. Quedamos sin novedad alguna, más que un gentil, luego que llegamos, se nos fue. Distribuyó el capitán su gente como la anterior noche. (Al margen: tres leguas y media)

Día 4. A las diez de la mañana salimos de este paraje ejecutando el rumbo del noroeste cuarta al oeste, sin embargo de los muchos rodeos que nos hacía dar lo estrecho del arroyo de donde salimos, siendo todo él muy pedregoso. Como a las doce y media del día subimos un cerro, desde donde descubrimos una cañada de hermosa vista, a la que llegamos a las dos y media de la tarde, parando el real a la sombra de un frondoso álamo, que su tronco tendría dos varas de grueso. Esta cañada se dedicó a san Isidoro $^{64}$, la que tiene agua suficiente para siembras. Regulo desde San Ricardo a esta cañada de San Isidoro cuatro leguas. Quedamos sin novedad, guardando las órdenes que el capitán da de noche a sus soldados. (Al margen: cuatro leguas)

Esta cañada está tendida noroeste-sueste y, habiendo tomado su altura, lo es de 31 grados, 28 minutos de latitud norte ${ }^{65}$. Se halla en ella abundancia de árboles llamados sauces, alisos y álamos. Es paraje a propósito para fundar una misión por tener mucha tierra de siembra de humedad, acompañándole dos arroyos que, teniendo su origen en la Sierra Madre, que es la más próxima, se esparcen por las dos orillas de la cañada, incorporándose éstos en la medianía, la que puede bañar mucha tierra de riego y mantener ganado.

Día 5. Salieron seis soldados a reconocer la tierra y buscar aguaje para la jornada venidera. Estos vinieron al ponerse el sol y dijeron que esta cañada en que estábamos avanzaba más de cuatro leguas, acompañándole siempre el agua, y que, habiendo visto un río caudaloso, que se les hacía difícil no fuera su curso a expirar en la mar de la costa occidental, lo que nos dio esperanzas para poder caminar el día de mañana. A las cuatro y media de esta tarde se murió un indio de la misión de Santa Gertrudis ${ }^{66}$, habiendo confesado y recibido la santa extremaunción.

64 El padre Crespi lo cristianó san Isidoro porque llegaron el día de la festividad del santo. En la actualidad, San Isidoro es utilizado de forma esporádica por los rancheros. La segunda expedición terrestre, con fray Junípero Serra y el gobernador Portolá, llegó el 29 de mayo, vigilia de San Fernando, por lo que este último pidió que se le pusiese el nombre del santo monarca: "A este paraje dice el señor gobernador habérsele de llamar San Fernando, no sólo por haber llegado la víspera del santo y celebrado aquí su día, sino por ser el Rey de los parajes de California”. Palou: Recopilación de noticias ..., I, pág. 341. Pero añade: "Si se logra que la misión de Vellicatá quede con el nombre de San Fernando distinta de Santa María, me alegrará que ésta se llamase de San Pedro Regalado, y así por ahora sólo nombraré a este sitio el de el día de San Fernando".

65 El franciscano mallorquín tomó la altura de 31 grados y 5 minutos, siendo en realidad de 30 grados, 45 minutos y 56 segundos (Lazcano: La primera entrada ..., pág. 257, nota 63).

66 Fray Juan Crespi también recogió este fallecimiento, pero difiere de su lugar de nacimiento: "Hoy enterré en este arroyo a un Gerónimo, casado que era, de San Xavier de la misión de San Ignacio, recibidos los santos sacramentos de la penitencia y extremaunción, dejando fijada una cruz en su sepultura”. Palou: Recopilación de noticias ..., I, pág. 287. 
Día 6. Se enterró éste y salió el capitán con seis soldados para componer un mal paso que, por donde habíamos de caminar, había. A las ocho y cuarto salimos de este paraje ejecutando el rumbo del oeste cuarta al noroeste a fin de rodear un barranco que había. Pasamos éste y entramos en el arroyo de San Isidoro, en donde, a las doce y media, paramos en un paraje ${ }^{67}$ del mismo arroyo. Todo el camino lo ejecutamos por el referido arroyo, ejecutando el rumbo del oeste, declinando para el sur y algunas veces inclinándonos para el norte a causa de las muchas vueltas que nos hacía dar el arroyo. Tiene algunos bocados de tierra que poder sembrar, sin tener más defecto que el agua haber tomado el resabio de tener punta de salobre, pero corre con más violencia por juntársele otros dos arroyitos que la hacen ser más cuantiosa, y se hallan muchos árboles de robles, álamos y sauces con algunos mezquites. Habrá desde San Isidoro a este paraje donde nos hallamos del mismo arroyo tres leguas. Quedamos sobre el cuidado de las órdenes que distribuye el capitán para de noche. (Al margen: 5 leguas)

Día 7. Por la mañana salió el capitán con seis soldados a buscar jornada para el día de mañana. Vino dicho señor y dijo había visto un río caudaloso que distaría de nosotros como dos leguas, y que en los cerros inmediatos a él había visto muchos lobos, y que el río estaba intrincado en lo interior de la Sierra Madre. Estos cerros, según parecen, tienen indicios de minerales. Quedamos con las precauciones debidas.

Día 8. A las ocho de la mañana salimos al paso de la recua del arroyo que desciende de San Isidoro, ejecutando el rumbo del nornoroeste. Habiendo andado como una legua, dimos con el que dicen es río68, pero le faltan muchos requisitos para ello. Sin embargo, se le puede dar tal nombre respecto de los arroyos que en Californias se ven, porque, además de ser éste caudaloso y violento, corre con mucho ímpetu, teniendo su nacimiento en la Sierra Madre. Está abastecido de mucha madera de robles, sauces, alisos y encinos, pero le falta lo mejor, que son las tierras de siembra. Está sumamente encajonado y cercado de cerros, que no le dan lugar para que se esparza su agua por encontrarse con las faldas de los cerros, pues, en dos leguas que andaríamos de él, lo hubimos de cruzar trece ocasiones. Su ancho será en partes de dos, tres, ocho y diez varas, formando algunos brazos en los que corre con igual impulso el agua. Luego como entramos en este río, ejecutamos el rumbo del oeste, cuarta al noroeste, y a las doce y cuarto paramos en él, al pie de un frondoso encino que se halla al margen del río. Ignoramos si cercano a la playa tendrá algunas tierras a propósito para misión. A las dos de la tarde salieron los seis soldados exploradores a reconocer la tierra y buscar paraje para rendir la jornada de mañana. Quedamos sin novedad alguna, sólo con el cuidado de los exploradores, que no habían venido. Regulo desde el paraje donde salimos esta

67 Fray Juan Crespi la bautizó como: "la cañada y arroyo de San Vicente Ferrer"; y fray Junípero Serra, la cañada de Santa Petronila. Palou: Recopilación de noticias ..., I, págs. 287 y 341.

68 En la actualidad, se conoce como arroyo de San Antonio de los Murillo, y es el principal afluente del arroyo de Santo Domingo. 
mañana a éste, que se dedicó a san Dionisio ${ }^{69}$, tres leguas. Dispuso el capitán sus soldados en la forma que las noches anteriores. (Al margen: 3 leguas).

Día 9. A las diez llegaron los exploradores, los que dieron noticia de que este río angostaba y tenía un mal paso, [y] que habían visto un arroyo a donde poder parar, pero que era preciso el abrir camino. Esto obligó al capitán a no salir hasta la mañana del día venidero. Tomé la altura de este río y lo es de 31 grados, 32 minutos ${ }^{70}$. Quedamos sin ninguna novedad, guardando las órdenes que el capitán da para de noche.

Día 10. Se celebró el santo sacrificio de la misa como el día antecedente y salió el capitán de mañana con ocho soldados para abrir camino. A las nueve de la mañana salimos ejecutando el rumbo del oeste, inclinándonos para el norte. Habiendo caminado como una legua, llegamos al pie de una cuesta, en la que estuvimos parados, dando tiempo para que los soldados finalizaran el camino que, con sumo trabajo, estaban abriendo. A las once la subimos y dimos vista a un arroyo en que había bastante agua, al que llegamos a la una de la tarde y paramos el real. A las cuatro salió el capitán con seis soldados, el que vino a las seis y dijo empezaba a abrir la tierra. A estas horas llegaron al real dos indias y tres párvulos gentiles, a los que se les dieron sus abalorios y se despacharon ${ }^{71}$. Este arroyo se dedicó a san León ${ }^{72}$ y habrá desde San Dionisio a éste donde nos hallamos tres leguas. Quedamos sin novedad, con las precauciones que intima el capitán a sus soldados. (Al margen: 3 leguas)

69 Así lo bautizo fray Juan Crespi. Palou: Recopilación de noticias ..., I, pág. 288

70 La altura tomada por fray Juan Crespi fue de 31 grados y 8 minutos. Palou: Recopilación de noticias ..., I, pág. 288.

71 Cuenta fray Juan Crespi que: "A poco de llegados, llegaron nuestros neófitos de a pie con una mujer gentil con tres muchachitas y un niño, todos rayados, las mujeres todas honestamente tapadas su honestidad, con unos hilos tupidos, colgados desde la cintura, tapando lo de delante, y detrás con pieles de coyotes, y venados, y otros animales. Del cuello llevaban colgados caracoles, y conchas del mar; el señor comandante les dio abalorios y listones; el niño llevaba el vestido que la naturaleza le dio, porque todos los varones así van; se les agasajó cuanto se pudo con comida que tomaron gustosos, y se quedaron con nosotros toda la tarde; son unos pobrecitos y miserables gentiles, muy mansos y humildes, y la tierra muy pobre de comistrajos, pues en estas últimas jornadas ya no se han visto mezcales, que es su pan cuotidiano”. Palou: Recopilación de noticias ..., I, pág. 289. Los indios pertenecían al grupo kiliwa, que, junto a los pa-ipai y a los diegueños (o kiliwa), forman la familia de los yumanos occidentales o norteños, que habitan el norte de la península de Baja California y el suroeste de los Estados Unidos. Sobre los kiliwa, véase Meigs, Peveril III: The Kiliwa Indians of Lower California, University of California Press, Berkeley, 1939. En cuanto a los diversos grupos yumanos, véase Laylander, Don: "Organización comunitaria de los yumanos occidentales: una revisión etnográfica y prospecto arqueológico”, en Estudios Fronterizos, n. ․ 24-25, Mexicali, 1991, págs. 31-60; y el libro de Garduño, Everardo: En donde se mete el sol ... Historia y situación actual de los indígenas montañeses de Baja California, Consejo Nacional para la Cultura y las Artes, México, 1994.

72 Se conoce como arroyo de Valladares. Aunque fray Juan Crespi creía que era un buen sitio para levantar una misión, la idea no prosperó. El paraje también le gustó al padre Serra, quien lo bautizó como San Andrés del Agua. “. Palou: Recopilación de noticias ..., I, pág. 343. 
Día 11. De mañana nos dieron noticia de que un indio de los intérpretes estaba enfermo de gran cuidado. Esto nos obligó a no salir y tomé al mediodía la altura de este arroyo de 31 grados, 35 minutos. A las once y media murió el indio que estaba enfermo ${ }^{73}$ y a las siete y cuarto salimos ejecutando el rumbo del noroeste, declinando para el oeste. Pasamos un cerro y entramos en tierra llana siguiendo el rumbo del oeste cuarta al noroeste. A las cinco y media de la tarde subimos un cerro, en el que paramos por estar próximo a un ojito de agua ${ }^{74}$. Aquí vino un gentil a vernos, el que, habiendo inquietado al que teníamos, se desertaron a la noche uno y otro ${ }^{75}$. Caminaríamos para llegar a este paraje tres leguas y media. Quedamos sin novedad alguna y se dispuso la gente como la noche pasada. (Al margen: 3 leguas y media)

Día 12. A las seis y media de la mañana salimos de este paraje para buscar agua. Seguimos el rumbo del sudoeste, dándonos esperanzas los muchos arroyos que había a que encontrásemos agua. A las once y media paramos en un cerro que formaba mesa, de donde salieron seis soldados a buscar agua. Estos vinieron y dieron noticia de que la habían encontrado y que era preciso el abrir batequi. Fueron con la caballada y al anochecer llegaron. El camino que hicimos para llegar a este paraje $^{76}$ fue por unas grandes llanadas. Caminaríamos como tres leguas. Quedamos sin novedad alguna, guardando las órdenes del capitán.

Día 13. A las nueve y tres cuartos de la mañana salimos de este paraje haciendo el rumbo del nornoroeste. A las dos llegamos al paso de la recua a una cañada bien esparcida pero sin agua. Todo el camino lo ejecutamos por entre cerros próximos a la costa del sur, siguiendo la esterilidad de la tierra, aunque nos socorrieron los mescales, de que nuestros indios estaban escasos, por ser su alimento y carecer de ellos seis días había. Paramos el real a media cañada. Salieron los soldados exploradores para registrar si al rumbo del norte encontraban agua en la cañada. Estos vinieron a las oraciones sin haberla hallado y con la noticia de que se esparcía por el dicho rumbo más de dos leguas. Considero desde el paraje de donde salimos a éste en donde nos hallamos cuatro leguas.

73 Fray Juan Crespi nos proporciona el nombre: "A este paraje antes de salir, enterré a un Manuel Valladares, indio casado que era con Juana, del pueblo de San Borja, de la misión de San Ignacio, recibidos los santos sacramentos de la penitencia y extremaunción, el que se enfermó en el paraje antecedente de San Isidoro, dejando una cruz fijada en su sepultura. Cuya muerte sentí con todo mi corazón, por los buenos oficios que me había hecho en todo el camino, sirviéndome de intérprete". Palou: Recopilación de noticias ..., I, pág. 290. Cuando fray Junípero Serra pasó por el lugar, la sepultura: "La habían excavado o los gentiles o los animales y estaban dispersos los huesos, los que se han recogido y vuelto a enterrar, y echado sobre la sepultura mucho agua para tupir y entiesar la tierra, piedra, etc." (pág. 343).

74 Fray Juan Crespi fue tajante en su apreciación: "No lo nombré más que la Loma Alta". Palou: Recopilación de noticias ..., I, pág. 290.

75 El padre Crespi lamentó la partida del muchacho: "porque muy bien nos servía para los aguajes; el señor comandante lo había vestido muy bien, lo íbamos catequizando, y yo ya había creído lo había de bautizar”. Palou: Recopilación de noticias ..., I, pág. 290.

76 El paraje fue bautizado por fray Juan Crespi como San Angel a Clavasio; y el padre Serra lo renombró San Pacífico. Palou: Recopilación de noticias ..., I, págs. 291 y 344. 
Día 14. Amanecimos sin novedad y salieron los soldados exploradores para reconocer si en el remate de esta cañada que corre para el oeste encuentran agua. Al mediodía tomé su altura de 31 grados, 43 minutos $^{77}$. Como a la una vinieron los exploradores para ver si quería el capitán fuéramos al aguaje que habían encontrado, el que, informándose del terreno y atendiendo a la escasez en que estábamos, dispuso salir por lo muy fatigada que estaba la caballada, lo que ejecutamos a las cuatro y media de la tarde, dirigiendo nuestro camino al sudoeste cuarta al oeste. Nos anocheció sin haber llegado al aguaje y, como íbamos por tierra nada conocida y nunca habíamos caminado a estas horas, mandó el capitán a la escolta que nos acompañaba que todos se armasen en guerra, poniéndose las cueras y prontas las armas. Con esta precaución caminamos hasta las nueve de la noche, que llegamos al paraje que decían los exploradores ${ }^{78}$. Paramos el real y quedamos sin novedad alguna, guardando las órdenes que el capitán distribuye de noche. Regulo de donde salimos a este paraje en donde nos hallamos cuatro leguas. Se mantuvo en vela la caballada por ser el paraje en que se halla el agua arriesgado para que beba de noche. (Al margen: 4 leguas)

Día 15. De mañana se registró el paraje y dispuso el capitán no salir hoy por estar el sitio bien empastado para que la caballada pueda restaurar lo mal que ha pasado cuatro días. Reconocí el aguaje, el que se halla en una poza de gran ámbito tendida del noroeste al sueste; su profundidad, según me parece, será de veinticuatro codos. Se crían en ella galápagos ${ }^{79}$ y pescados blancos. Este paraje se dedicó a San Telmo. Si el agua que se halla en esta poza pudiera salir, fuera suficiente para bañar tierras que poder sembrar y coger millares de fanegas de grano. Por las orillas del agua se encuentra mucho salitre, pero, no haciendo caso de él, es suficiente para sembrar la tierra, que no lo tiene. Al mediodía observé en la latitud de 31 grados, 35 minutos $^{80}$, menor que la de donde salimos a causa de haber hecho la jornada para el sudoeste cuarta al sur. A la tarde salió el capitán a explorar la tierra y me dijo que, torciendo su curso esta cañada para la costa occidental, corría el agua con abundancia y que ésta bañaba suficiente tierra de siembra, que también tenía bastante de humedad, que era famoso paraje para una misión si se consiguieran los fines de nuestro destino, y que de lo alto de un cerro había visto la mar, pareciéndole que próximo a la cañada había visto un puerto. El sitio es muy fértil

77 La altura registrada por fray Juan Crespi fue de 31 grados y 17 minutos N. Palou: Recopilación de noticias ..., I, pág. 292.

78 Fray Juan Crespi lo cristianó: "La Poza del llano de San Telmo"; mientras fray Junípero Serra lo bautizó como Santos Gorgomienses. Palou: Recopilación de noticias ..., I, págs. 293 y 345.

79 Según fray Juan Crespi: "Tiene mucho tular alrededor, muchas tortugas, y también decían que pescado". Palou: Recopilación de noticias ..., I, pág. 292. En realidad, no eran galápagos, sino tortugas acuáticas de la especie Kinosternon flavescens, abundantes en los arroyos permanentes que bajan de la sierra de San Pedro Mártir.

80 El padre Crespi observó 31 grados y 11 minutos $\mathrm{N}$, siete menos que al otro lado del llano. Palou: Recopilación de noticias ..., I, pág. 293. 
y ameno de árboles. Quedamos sin novedad alguna, observando las órdenes que el capitán da de noche a sus soldados.

Día 16. De mañana se dijo misa y a las ocho y media salimos dirigiendo nuestro camino al nornoroeste por permitirlo la tierra, que se ancha por las mesas de los cerros. A la una y media llegamos a otra cañada muy bien empastada, con algún salitre, que se dedicó a san Rafael ${ }^{81}$. Poco antes de llegar, corrieron los soldados [a] unos gentiles y se consiguió que se cogiera un viejo tan sumamente ensoberbecido que a todos nos causó disgusto el ver los ademanes que hacía, porque no mostraba menos que ser un gran hechicero de sus ídolos. Habiendo llegado a esta cañada los soldados exploradores, trajeron cuatro gentiles, dos mujeres y dos varones, siendo el uno todavía párvulo, y, aunque las mujeres mostraban ser más dóciles, se reconoció en el indio la propia rabia que el viejo, pues, habiéndose apoderado la cólera de él, se arrancaba los trozos de cabellos ${ }^{82}$. Esto obligó al capitán (para que no pensasen que nosotros éramos gente que pretendíamos hacerles daño) a dar unas bujerías de abalorios al viejo y [a] las dos mujeres, despachándolas para sus rancherías. [En] el abra de esta cañada que corre para la playa se vio una poza de agua dulce y, poco más abajo, un ojo de agua que, corriendo su curso por la superficie de la tierra, como a las cincuenta varas, se sumergía. El sitio, según dicen los que tienen inteligencia, es famoso paraje para una misión por encontrarse tierra de humedad para sembrar algunas fanegas. Se encuentran algunos árboles, alisos, álamos y sauces. Caminaríamos hoy para llegar a este paraje tres leguas por los rumbos del norte [y] nornordeste, $\mathrm{y}$, aunque nosotros no podemos registrar estos parajes por no dilatar nuestro camino, parecen ser mejores vecinos ${ }^{83}$ a la costa occidental. Sigue la honestidad de las indias y el gentil que quedó en nuestra compañía estaba tan embijado que parecía diablo. (Al margen: 3 leguas)

Día 17. Por la mañana le preguntamos al indio gentil por señas que en qué paraje había agua y, no pudiéndosele entender por carecer de intérprete que les hable, por haberse huido de nuestra compañía los indios cristianos el día 15 y los que quedaron no entenderles cosa alguna, viendo que no daban esperanzas algunas de

81 Así lo bautizó fray Juan Crespi: "para que con el tiempo sea una muy grande misión; con mucha gentilidad, según lo demuestran los muchos rastros, y caminos trillados". Palou: Recopilación de noticias ..., I, pág. 294. Fray Junípero Serra lo nombró Santa Margarita y recogió en su diario el encuentro con un indio que bailó largamente todos los alimentos, y quien le comunicó que en su lengua se llamaba el lugar Matiropi. Palou: Recopilación de noticias ..., I, pág. 346

82 Añade fray Juan Crespi que: "el gentil grande no sé en qué se pudiese diferenciar de un demonio el más feamente pintado, porque no más de mirarle la cara queda uno horrorizado, con unas fajas de embijes de blanco, amarillo y colorado". Palou, Recopilación de noticias ..., I, pág. 294. Sobre la visión de los indios como demonios, véase Salvador Bernabéu Albert: "El diablo en California. Recepción y decadencia del maligno en el discurso misional jesuita", en Salvador Bernabéu (editor), El Septentrión Novohispano: ecohistoria, sociedades e imágenes de frontera, Consejo Superior de Investigaciones Científicas, 2000, págs. 139-174. Los indios encontrados eran pa-ipai, grupo que formaba parte de la más amplia familia de los yumanos norteños.

83 En el texto: "veensos". 
llevarnos al aguaje, se le dieron al párvulo y a él sus abalorios y se despacharon. A las ocho de la mañana salimos de esta cañada y, habiendo ejecutado el rumbo de nornoroeste, unas veces inclinándonos al norte y otras declinando al noroeste, a la una y media de la tarde llegamos a un valle bien empastado, con mucho salitre, que se dedicó a santo Toribio ${ }^{84}$. En él encontramos una poza de agua inclinada a un cerro, descendiendo de un ojo de agua que coge el resabio de amarga con punta de salitre. Pero más abajo había una ciénega de agua menos mala. Esta cañada y las dos que quedan pasadas corren nordeste-sudoeste. Por el camino vimos cercanos a esta cañada dos arroyos con arboleda. A la vista, su verdor parecía tener agua, pero son muy angostos y encerrados. Esta cañada de Santo Toribio, al parecer, tiene algunas tierras de humedad, pero todo ello de poco provecho. Ignoramos si cercano a la playa correrá el agua bañando algunas tierras, porque a la vista no es cosa apreciable. Regulo desde San Rafael a este paraje cinco leguas. Quedamos sin novedad alguna, ejecutándose las órdenes que da el capitán para de noche. (Al margen: 5 leguas)

Día 18. A las ocho de la mañana salimos de este paraje ejecutando el rumbo del nornoroeste y, no pudiendo seguirlo por impedirlo los cerros, tomamos el del noroeste para una gran llanura que corría a este rumbo. A las doce del día llegamos a otro paraje muy abastecido de árboles, con el agua en ciénega, que se dedicó a santa Isabel, cuya latitud observada es de 32 grados $^{85}$. Una legua distante del paraje donde habíamos salido, vimos dos casas e, inclinándonos a ellas, un viejo gentil al que, diciéndole que si quería acompañarnos, dio muestras de que sí, porque, previniéndose con sus armas de arco y flecha, nos guió a este paraje. Es de admirar ver cómo se dan maña estos indios para fabricar unas ollas de barro bien labradas, agregándosele la curiosidad que del corazón del mescal sacan sus hebras y tejen unos lienzos de labor como encontramos en este viejo. Esta ciénega de Santa Isabel es paraje a propósito para establecer misión, porque, sin embargo de no haber visto más agua que la de la ciénega y algunos pozos que están a la falda de un cerro, tiene suficiente y abundante tierra de humedad en que poder sembrar algunas fanegas de grano, demás que su vista se esparce tanto y corre la cañada avanzando tanta tierra, que parece imposible que con cultivo y registro se deje de hallar arroyo al principio o fin de la cañada, sin mostrar, por lo que se ve, la tierra nada de salitre. Salieron a verla y dicen que en parajes corre el agua y en otros se sume, por lo que no admite duda que al principio o fin de la cañada corre el agua.

84 Fray Junípero Serra lo bautizó San Bernabé, aunque este topónimo, como el que le dio fray Juan Crespi de Santo Toribio, no prosperó. Palou: Recopilación de noticias ..., I, págs. 348 y 296. En la actualidad se conoce como Llano Colorado.

85 Fray Juan Crespi escribe que: "A todos cuadró mucho el paraje para una misión. No se han visto mezcales hoy. Púsele el nombre la ciénaga de Santa Isabel reina de Hungría, por rezar hoy de su translación, para con el tiempo sea una buena misión. A este paraje llamó el padre presidente San Guido. Tomé la altura en esta ciénega, y salió la altura del norte de 32 grados cabales". Palou: Recopilación de noticias ..., I, pág. 296. En este lugar fundaron los dominicos Miguel Hidalgo y Joaquín Valero la misión de San Vicente Ferrer en 1780. Además, los españoles levantaron un fuerte de adove donde vivía un destacamento de soldados. 
Hoy caminaríamos para llegar a este paraje cuatro leguas. A la tarde se despachó al gentil, dándole sus abalorios. Quedamos sin novedad, guardando las órdenes del capitán para la noche. (Al margen: 4 leguas)

Día 19. A las ocho de la mañana salimos caminando al noroeste, declinando para el oeste, ejecutando este rumbo por serranía. Como a las tres leguas encontramos una cañada con apariencias de buena, aunque mentidas por no tener en lo que se reconoció y a la vista se vio ningún agua, aunque se halla arboleda de alisos. A la una y media de la tarde llegamos a otra cañada bien vestida de estos árboles, con mucho pasto, pero carece del agua. La ninguna noticia que de ella teníamos nos obligó a hacer mansión y salieron los exploradores con el capitán a buscar aguaje en que pueda beber la caballada, y dieron noticia de no haber encontrado más que un pocito que con dificultad alcanzaría para beber nosotros. Esta cañada está muy encajonada y rodeada de cerros. Se le puso el nombre de los Alisos $\mathrm{Secos}^{86}$. En esta jornada se han visto algunos cerros de hermosa vista y de uno se cogió una piedra que demuestra ser rico mineral. Sigue la esterilidad de la tierra. Andaríamos para llegar a este paraje cinco leguas de camino incómodo. Quedamos sin novedad, con toda la gente distribuida como ordena el capitán para de noche.

Día 20. A las siete y media de la mañana salimos de este paraje para proseguir nuestro camino, el que ejecutamos al noroeste por la cima de los cerros. Habiendo caminado como dos leguas al expresado rumbo, declinamos al oeste por no poderlo ejecutar. Avistamos la mar muy próxima a nosotros y una punta de un cerro que se avanzaba en él la mar al noroeste cuarta al oeste y, habiendo encontrado en una cañada que bajamos dos pocitos de agua, nos obligó a parar por estar necesitados de ella toda la gente. Mandó el capitán toda la escolta de exploradores fueran a ver si por un abra que hacía encontraban agua y camino, los que, habiendo llegado a las avesmarías, dieron la noticia de haber encontrado uno y otro, pero que el agua distaría de nosotros tres leguas. A las horas que paramos el real fue a las doce del día por causa de estar amenazando ruina de esterilidad la sierra y camino $^{87}$. Andaríamos dos leguas. Quedamos sin novedad, observando las órdenes que el capitán distribuye para de noche. (Al margen: 2 leguas)

Día 21. A las seis y media de la mañana salimos ejecutando el rumbo del noroeste. A poco torcimos al nornoroeste por haber entrado en el arroyo que está el agua. A las diez y media paramos en este arroyo, que se dedicó a san Anselmo ${ }^{88}$. La tierra de él no es muy buena para sembrar por estar encerrada en el cajón del arroyo

86 Fray Juan Crespi lo llamó: "el Arroyo Seco de los Alisos"; y el padre Junípero Serra, San Nazario de los Alisos. Palou: Recopilación de noticias ..., I, págs. 297 y 349.

87 El padre Crespi bautizó el paraje como arroyo y cañada del beato Jacobo Ilírico y observó la altura de 32 grados y 8 minutos N. Fray Junípero Serra lo cristianó San Antonio de los Trabajos. Palou: Recopilación de noticias ..., I, págs. 297 y 349.

88 El topónimo elegido por fray Juan Crespi fue: "el arroyo de los Alisos y ojo de agua de San Anselmo"; mientras fray Junípero Serra lo renombró San Basilio. Palou: Recopilación de noticias ..., I, págs. 298 y 350. 
y no ser suficiente el agua. Los soldados que venían con la recua nos dijeron que, próximo al paraje de donde salimos, había un aguaje corriente y que la causa de no haberlo visto era por estar tapado con algunos pastos. Hoy observé en la latitud de 32 grados, 16 minutos $^{89}$, y regulo haber caminado tres leguas. (Al margen: 3 leguas)

La mañana de este día se encontró muerto [a] un indio cristiano ${ }^{90}$ que estaba enfermo días había. Salió el señor capitán y trajo noticia de lo que se sigue.

Día 22. A las ocho de la mañana salimos de este paraje, ejecutando el rumbo del nordeste. A poco rato torció al norte y, habiendo llegado ${ }^{91}$ [sic] como una y media legua, llegamos a la cañada que había visto el día antes el señor capitán, la que se dedicó a san Francisco Solano ${ }^{92}$; la que, habiendo reconocido, se vio ser muy a propósito para una misión, pues, en lo que registramos, que sería como una legua, se hallaron dos ojos de agua. El uno salía de la superficie de la tierra, brotando alguna porción, pero como a las ocho varas se consumía, y el más grande lo arrojaba por un conducto que venía de por medio de la cañada, corriendo como doscientas varas, y se sumerge en la tierra [y] se le junta a éste otro arroyito que desciende de unos cerros, el cual está muy coronado de árboles. Ignoramos si tendrá agua, por no haberlo reconocido por la parte del este de esta cañada. Se vieron muchos árboles de sauces, alisos, álamos y encinos. A la tarde salió el capitán con los exploradores a reconocer la tierra y, habiendo venido, me dijo que esta cañada corre su curso para la playa de la contracosta, que sigue muy fértil de los expresados árboles, y que en el circuito de ellos forma el agua una ciénega, en que, según parecía a la vista, se podía sembrar. Ignoramos si vecinos ${ }^{93}$ a la playa de la contracosta corre el agua con más abundancia. La vista de esta cañada es hermosa, muy bien empastada, apuntando algún salitre, pero éste no le quita su valor por no necesitar (en caso de poner misión) de la tierra, que está maleficiada de este defecto. A las horas que llegamos fue a las diez de la mañana. Tomé su altura de 32 grados, 20 minutos $^{94}$. Hoy caminaríamos una legua y media, y quedamos sin novedad guardando las órdenes del capitán. (Al margen: 7 leguas y media).

89 El resultado de la observación de fray Juan Crespi fue de 32 grados y 8 minutos N. Palou: Recopilación de noticias ..., I, pág. 297.

90 El indio se llamaba Enrique o Merico, y era -según Crespi- del pueblo de San Rafael, de la misión de Santa Gertrudis. Estaba soltero. Recibió los sacramentos de la penitencia y la extremaunción, y se colocó una cruz sobre su sepultura. Palou: Recopilación de noticias ..., I, pág. 297.

91 Error del copista: debería poner "caminado".

92 Así lo bautizó fray Juan Crespi: "esperando que con el tiempo sea muy grande misión”. Su compañero Serra lo cristianó San Antonio de Padua. El paraje despertó gran expectación: "ya les parece corta expresión la de misión y dicen deber llamarse la ciudad de San Antonio de Padua". Palou: Recopilación de noticias ..., págs. 299 y 352. El valle fue explorado posteriormente por el dominico Luis de Sales, eligiéndolo para levantar una misión, que se dedicó a santo Tomás de Aquino. Su fundador fue José Loriente en 1791, siendo trasladada en 1794 a otro paraje para evitar las frecuentes inundaciones, pero siempre en el valle de Santo Tomás.

93 En el texto: "veensos".

94 La medición del padre Crespi fue de 32 grados y 10 minutos $\mathrm{N}$. La correcta es menor: 31 grados y 33 minutos $\mathrm{N}$. 
Día 23. A las ocho de la mañana salimos de este paraje ejecutando el rumbo del noroeste cuarta al norte y, habiendo andado como una legua y media, llegamos a otro paraje que hace un valle en el que se halla el agua en ciénaga y una poza de donde sale el agua caliente y, dejándola enfriar, es bien delgada. Está todo rodeado de muchos encinos y alisos, y, según dicen los inteligentes, puede formarse una buena misión en San Francisco Solano por lo próximo que están estos dos parajes, y puede ayudar la siembra de éste a la de aquella misión. Es bien capaz para mantener cosecha y ganado, el cual se dedicó a san Jorge ${ }^{95}$. Salió el capitán con los exploradores y, habiendo venido, me dijo cómo había visto el mar y en él una gran ensenada con una isla, la que discurro será la de la ensenada de las Vírgenes ${ }^{96}$, y que la sierra corría hasta fenecer en la mar. Quedamos sin novedad, guardando las órdenes que da el capitán para de noche. Hoy caminamos una legua y media. Cuando llegamos a este paraje, de lo alto de un cerro nos llamaban dos gentiles, pero, aproximándonos, se huyeron ${ }^{97}$. (Al margen: una legua y media)

Día 24. Esta noche la hemos pasado con bastante cuidado por haber la caballada dado dos estampidas. Se mandaron a los exploradores fuesen a ver si había algún abra para transitar la sierra, los que vinieron a las doce y dijeron que había camino y agua distante de nosotros como tres leguas. Esto fue causa de no salir esta tarde por no arriesgarnos a que nos coja la noche en el camino y que nos suceda algún accidente no esperado. En este paraje hemos visto cuatro casas de indios y quedamos con el cuidado de las órdenes del capitán.

Día 25. Amanecimos lloviendo, por lo que nos impidió el que saliéramos, habiendo llevádose hasta las tres de la tarde en la misma conformidad. La mañana de este día, una mula que uno de los soldados de vela tenía amarrada, amaneció con un flechazo, no pudiendo averiguar de los centinelas quiénes lo darían por estar del real ciento cincuenta pasos distante la mula, a la que se le sacó y sigue buena. El no salir este día es por lo muy mojados que estamos y tener las mismas precauciones que el antecedente día, y quedamos sin novedad con las órdenes y centinela avanzada que ha puesto el capitán.

Día 26. La noche antecedente nos llovió, poniéndonos en cuidado la caballada por haber dado tres estampidas. A las diez de la mañana salimos por encima de unos cerros, ejecutando el rumbo del nordeste. A poco torcimos al nornordeste $y$, cuando bajamos a la cañada, torcimos al norte. A las dos y media llegamos a un

95 Fray Juan Crespi bautizó el paraje como: "el valle y ciénaga de San Jorge", mientras el padre Serra lo dedicó a San Atenógenes, Obispo y Mártir, a petición del sargento José Francisco de Ortega. Palou: Recopilación de noticias ..., I, págs. 300 y 352. Ninguno de estos nombres ha permanecido, pues en la actualidad se conoce como valle de la Grulla, topónimo que ya aparece en la citada obra de fray Francisco Palou, pág. 208. Según Carlos Lazcano: "Es muy probable que el nombre de la Grulla le haya sido puesto por los soldados, al ver a una de estas aves, u otras parecidas, en el sitio". (La primera entrada ..., pág. 272).

96 Primera mención a la Ensenada de Todos los Santos.

97 Este sería el primer encuentro con los indios diegueños o kumiai. 
arroyo, que se dedicó a los Mártires ${ }^{98}$, el que corre al oesnoroeste, el que estaba bien abastecido de encinos y alisos, pero de poca agua por no tenerla más que en pozas. Se hallan dos cerros vestidos de ramajos; no tiene cosa especial. Caminaríamos tres leguas. Quedamos sin novedad, observando las órdenes del capitán. (Al margen: 3 leguas)

Día 27. De mañana se mandaron a los soldados exploradores para ver si se encontraba camino y agua. Estos llegaron a las nueve y dieron noticia de que parecía abría la tierra para poder caminar, [y] que no daba esperanza de encontrar agua por estar toda la tierra seca y estéril. Esto nos obligó a cargar el agua en botas y barriles, y a las once de la mañana salimos de este arroyo de los Mártires ejecutando el rumbo del norte. Se adelantó el capitán con diez soldados para ver si encontraban agua, pero, habiendo andado como dos leguas, se hallaron cercados de la sierra, que por todos los rumbos del primer y cuarto cuadrante no daban paso para poder transitar. Esto nos movió a hacer mansión en un pedazo de llano a propósito para poder formar el real ${ }^{99}$, en donde paramos a las dos de la tarde sin agua. A esta hora salieron los soldados exploradores a ver si podían transitar la sierra. A la noche llegaron y dieron noticia de que no habían encontrado paso por ser todo un conjunto de cerros ásperos que fenecen en barrancos, y que no habían podido bajar por cerro alguno, impidiéndolo lo expresado. Quedamos sin novedad, guardando las órdenes del capitán para de noche. (Al margen: 2 leguas)

Día 28. Salieron con la orden del capitán los soldados exploradores, y yo en su compañía llevando el encargo de ver la mar y la isla marcarla, y el cabo de la escolta de buscar aguaje y camino. Y habiendo llegado a la playa, vi una isla, la que relevé y debía ser la de Todos Santos, sobre la ensenada de este nombre; pero hallábamonos confusos por tener un mapa mal situado ${ }^{100}$. Se encontró camino y una legua distante del paraje un ojo de agua. Al anochecer vinimos al real, dándole esta noticia al señor capitán. Quedamos sin novedad, observando sus órdenes con el cuidado de la caballada.

Día 29. Salimos para el aguaje que demoraba al oesudueste, en donde, habiendo caminado una legua, paramos a sus inmediaciones ${ }^{101}$. La noche pasada

98 Fray Juan Crespi dedicó el arroyo a los santos mártires san Cleto y Marcelino; y el padre Serra, a san Gervasio. Palou: Recopilación de noticias ..., I, págs. 301 y 353. I, pág. 274.

99 Fray Juan Crespi llamó al paraje: "el Bajial sin Agua". Palou: Recopilación de noticias ...,

100 Esta salida la recoge fray Juan Crespi: "el señor comandante ordenó fueran seis soldados con el pilotín don José Cañizares, supuesto no dar paso la sierra, si podían divisar de más cerca de lo alto de los cerros, la gran ensenada que de un cerro cerca del paraje de San Jorge había visto, para saber si por ella se podría caer a la playa, y si encontraban agua para proseguir el camino". Palou: Recopilación de noticias ..., I, pág. 301.

101 Fray Juan Crespi lo llamó el: "Ojito de agua del arroyo de San Pedro Mártir"; y fray Junípero Serra: "Santa Miguelina, o Micaelina”. Palou: Recopilación de noticias ..., I, págs. 302 y 353. En la actualidad se conoce como el aguaje de la Yerbabuena, en el arroyo de la Rinconada, en el extremo suroeste del valle de los Gavilanes. Lazcano: La primera entrada ..., pág. 274, nota 124. 
dio la caballada dos estampidas, lo que nos pone en mucho cuidado. No salimos hoy por lo muy necesitada que está de agua la mulada. Quedamos sin novedad, guardando las órdenes del capitán, el que salió a las dos de la tarde para la playa a cerciorarse de lo que llevo expuesto. (Al margen: 1 legua)

Día 30. De mañana se dijo la santa misa. Pasamos lo restante de la noche con bastante cuidado por estar inquieta la caballada. A la tarde vino el señor capitán dando noticia de un aguaje que habían encontrado cercano a la orilla del mar, pero que distaría de nosotros como siete leguas. Quedamos sin novedad, guardando las órdenes del capitán. El agua se encuentra en un bosque circundado de encinos y alisos. Este paraje se dedicó a san Prudencio.

Día $1 .^{\circ}$ de mayo. Se celebró el santo sacrificio de la misa y a la una de la tarde salimos ejecutando el rumbo del oesudueste para salir a la marina. Habiendo andado como tres leguas, paramos el real a las inmediaciones del mar ${ }^{102}$. Cuando bajamos a la playa, vimos una gran polvareda de gentiles. Esto y el recelo que teníamos de que la gentilidad estaría cargada a la marina, dispuso el capitán hacer con los aparejos en resguardo un recinto provisional de atrincheramiento ${ }^{103}$. Quedamos con todo cuidado y seis centinelas, siendo la una avanzada. (Al margen: 3 leguas)

Día 2. A las seis y media de la mañana salimos ejecutando el rumbo del norte [y] nornoroeste en demanda del aguaje, al que llegamos a las nueve y media de la mañana, habiendo caminado a los expresados rumbos tres leguas de tierra llana. Próximos a la marina reconocimos el aguaje ${ }^{104}$ ser bueno, abundante y cercano a la playa, junto a una punta que forma un puerto resguardado del viento noroeste, paraje cómodo para hacer aguada. Al mediodía tomé su altura, estando al lesnordeste de dos islas que deben ser las de Todos Santos, cuya latitud es de 32 grados, 26 minutos. Quedamos sobre el cuidado de la caballada, habiendo a puestas del sol formado en nuestro resguardo con los aparejos un atrincheramiento. En lo alto de un cerro se han mantenido unos gentiles dando gritos, por lo que ordenó el capitán poner guardias dobles armados con sus cueras, y todos al cuidado de los indios. (Al margen: 3 leguas).

Día 3. No salimos por no tener paraje conocido y salieron los exploradores a buscar paraje para la jornada venidera, los que a las diez llegaron y dieron noticia de que en la punta del norte de esta ensenada habían encontrado un aguaje. A la tarde salió el señor capitán a ver si la tierra prometía tránsito dejando la marina, el

102 El real fue plantado en un bajial a una legua de la playa, que fue bautizado por fray Juan Crespi como: "el Bajial de los Santos Apóstoles", situado en la parte norte del valle de Maneadero. Palou: Recopilación de noticias ..., I, pág. 302.

103 Según fray Juan Crespi: "Al bajar la última cuesta oímos gritar a unos gentiles que venían haciendo una gran polvareda por la ensenada, siguiendo el mismo camino y rastro de los exploradores de ayer; así que los gentiles nos vieron, se volvieron como venados por el mismo camino que habían traído". Palou: Recopilación de noticias ..., I, pág. 302.

104 Fray Juan Crespi lo bautizó: "La Santísima Cruz de las Pozas de la Ensenada de Todos Santos"; y fray Junípero Serra, la Visitación de María Santísima: "por que ya se me hace largo el tiempo de dedicar algún paraje a María Santísima”. Palou: Recopilación de noticias ..., I, págs. 303 y 354. 
que vino al ponerse el sol con el cuidado del real por haber visto algunos indios, y uno tan atrevido (que a no ser el cuidado con que siempre se camina, pudiera haber sucedido algún daño), pues, estando al abrigo de unos ramajos, reflejaron en que había puesto una flecha en el arco y que lo iba a enarcar contra el propio capitán. Quedamos con el cuidado que pide el caso, intimando el capitán a sus soldados lo que deben practicar si llega la ocasión de disparar, quedando dos centinelas avanzadas y la caballada próxima a nosotros con seis soldados en vela armados ${ }^{105}$.

Día 4. Se dijo misa como el día antecedente y a las nueve salimos ejecutando el rumbo del nornoroeste en demanda de la punta del norte de esta ensenada, a la que llegamos a las once del día ${ }^{106}$, habiendo caminado tres leguas de tierra llana, y tomé al mediodía su latitud de 32 grados, 29 minutos, nordeste-sudueste con las islas de Todos Santos, corriendo las dos puntas de esta ensenada noroeste-sudeste, y en la punta meridional se contaban once farellones en cordillera. A la tarde vimos en un cerro diecinueve gentiles que nos gritaban armados con arcos y flechas. Esto nos puso en cuidado y el capitán distribuyó su gente por lo que pudiera suceder. Los gentiles se fueron y formamos el real en atrincheramiento, guardándolo las centinelas dobles por lo que pudiere acontecer. (Al margen: 3 leguas)

Día 5. No salimos y fueron los exploradores con escolta y cabo a buscar camino, del que no trajeron noticia por habérselo impedido lo acantilado de los cerros que expiran en la propia mar. Quedamos con el cuidado del real. A la tarde se aparecieron los gentiles en el mismo cerro armados como el día antecedente, no mostrando otra cosa que querer pelear. Se fueron y se pusieron los centinelas dobles, guardando las órdenes que el capitán da para de noche.

Día 6. No salimos este día por carecer de paraje, el que fueron a buscar los exploradores con todo cuidado, quedando nosotros en el suyo. Estos vinieron y dieron noticia de haber encontrado un famoso valle distante de nosotros cuatro leguas, por lo que esperamos el día de mañana para salir en su demanda. Quedamos sin novedad, con las precauciones debidas, guardando las órdenes que da el capitán para de noche. Desde el día de ayer, exceptuando el padre, se han puesto todos, por carecer de víveres, a una ración tan limitada que sólo basta para no desfallecer, regulándose cada uno a ocho onzas de harina en dos tortillas diarias.

Día 7. Se dijo misa y a las siete y media salimos ejecutando el rumbo del norte-nornoroeste declinando al oeste, y, habiendo caminado como cuatro leguas, vimos en la mar una isla que debe ser la de los Coronados ${ }^{107}$, demorándome al nor-

105 Fray Juan Crespi tomó la altura de 32 grados y 14 minutos N. La real es unos 20 ó 22 minutos menos.

106 El paraje en donde plantaron el real fue bautizado por fray Juan Crespi: “las pozas de Santa Mónica". Fray Junípero Serra lo nombró la ranchería de San Juan”. Palou, Recopilación de noticias ..., I, págs. 304 y 355. En la actualidad el paraje, al noroeste de la ciudad de Ensenada, se conoce como San Miguelito.

107 También fray Juan Crespi recogió la vista de los Coronados: "que de lejos parecen una isla, y no son sino cuatro como dicen las historias". Palou: Recopilación de noticias ..., I, pág. 305. 
oeste. Bajamos a un valle muy bien empastado que se dedicó a san Estanislao ${ }^{108}$. Luego como salimos del paraje, se aparecieron en un cerro los gentiles dándonos gritos. Proseguimos con todo cuidado y las armas prontas. Éstos llegaron a este paraje en donde nos hallamos, tomaron su común asilo, que son los cerros, y desde él nos gritaban haciendo ademanes de tirar flechas, disparando una hacia donde estaba la caballada. Estuvimos sobre las armas hasta que se fueron. Paramos el real al pie de un gran encino, que es de la madera que abunda este valle ${ }^{109}$. Habiendo llegado a las once y media, quedamos sin novedad, guardando las órdenes del capitán para la noche bajo de dos centinelas en el atrincheramiento y cuatro en la caballada. Andaríamos cuatro leguas. (Al margen: 4 leguas)

Día 8. A las siete y media de la mañana salimos de este paraje ejecutando el rumbo del oesnoroeste y, habiendo andado como dos leguas y media, llegamos a las cuatro de la tarde a descubrir un arroyo que desemboca en el mar, el que, no teniendo bajada por donde íbamos, nos fue preciso el retroceder y parar el real a sus inmediaciones ${ }^{110}$ para el día venidero buscar bajada, por estar en una gran profundidad, el cual tiene hermosa vista. Todo el camino lo hicimos por unas lomas tendidas muy bien empastadas. Quedamos con todo cuidado observando las órdenes del capitán con centinelas dobles. (Al margen: 2 leguas y media)

Luego como salimos del paraje, nos empezaron a seguir y gritar dos gentiles, apareciéndose (en el paraje donde la noche pasada habíamos puesto el real) veintisiete que también nos seguían. Hicimos alto, dando el capitán órdenes a sus soldados para que la recua y caballada viniera incorporada con el real. Luego como nos vieron parados, se subieron al cerro y, no siguiéndonos ninguno, proseguimos nuestro camino. Mas a poco rato se aparecieron en otro cerro próximo por donde íbamos cruzando, dando los mismos gritos que antes. Esto movió al capitán a parar, juntando recua y caballada, poniéndolas en conformidad de resguardo. Y para que no presumieran que les teníamos miedo, mandó el capitán a los soldados se pusieran las cueras, tomando la adarga en la siniestra mano y en la diestra cazadas las escopetas, formados todos en línea de batalla. Salió el capitán con seis soldados lanceros a aproximarse al cerro en donde los gentiles esta-

108 El paraje, bautizado por fray Juan Crespi como san Estanislao, fue nombrado por el padre Serra de san Juan Bautista, añadiendo: "Dormimos bajo un muy copudo encino, y aquí nos faltó el privilegio de California de la exención de pulgas, por que nos llenamos de ellas, y algunas garrapatas". Palou: Recopilación de noticias ..., I, págs. 304 y 356. El jesuita extremeño Miguel del Barco comenta, con sorna: "Privilegio de la Providencia Divina no concedido, en cuanto a pulgas y chinches, ni aun a las ciudades más populosas de la Europa ni de la América”. Barco: Historia natural ..., págs. 15-16.

109 El padre Crespi escribió que llegaron: "a un grandísimo valle, hermosísimo de pasto, y en sus extremos de arboleda con su buen arroyo de agua, que se veía correr entre el tular que tiene, y poza de agua muy buena; sitio a lo que parece para otra muy buena misión. Tiene algunos encinos grandes, y paramos el real bajo de un muy grande y copudo encino, cerca del dicho arroyo". Palou: Recopilación de noticias ..., I, pág. 304.

110 Fray Juan Crespi lo llamó: "la mesa de paraje de San Juan Bautista". Palou: Recopilación de noticias ..., I, pág. 306. 
ban acampados, los que le tiraron a dicho capitán y su escolta tres flechazos. Los nuestros, prontos, adargaron, cruzaron las flechas y el capitán le disparó un tiro al más atrevido de los indios, correspondiendo con otro un soldado, los que no habiendo dado en ningún indio, sólo con el sonido de la bala fue suficiente medicamento para quitarse de encima semejante padrastro, que nos ocupaba el cuidado y atrasaban las órdenes por tenerlos a la vista. Nos estuvimos mantenidos en esta conformidad como tres horas, hasta que se fueron los gentiles y nosotros a nuestro camino.

Día 9. De mañana bajamos al expresado arroyo, que se dedicó a san Juan Bautista $^{111}$, el que es paraje muy deleitable y ameno, teniendo todas las preeminencias para poder fundar una misión, hallándose el agua en poza rica y abundante, acompañándole a esto buenas tierras de humedad y siembra, con abundancia de árboles. Andaríamos para bajar a este paraje una legua. Luego como llegamos, los indios de una ranchería que está en esta cañada de diecisiete casas se fueron a un cerrito. Determinó el capitán ver si los podía granjear con algunas cintas y abalorios, lo que consiguió, arriesgándose dicho señor a ir al pie del cerro a ponerle estas bujerías. Luego como las vieron, bajó uno por ellas y en señal de paz pusieron en el propio paraje unas flechas en señal de agradecimiento. Habiendo entre ellos corrido la noticia, a poco rato bajaron al real indias, párvulos e indios, a los que, habiéndoles dado sus abalorios, quedaron entre nosotros muy contentos ${ }^{112}$.

Día 10. De mañana salimos y seis gentiles en nuestra compañía, que nos dirigían al aguaje ejecutando el rumbo del nornoroeste, el que torcimos al oesnoroeste y los gentiles dándonos gritos y señalándonos por dónde habíamos de ir, hasta que a las dos de la tarde llegamos a una cañada muy próxima a la marina, en la que, señalándonos el agua los que nos acompañaban, se despidieron y se fueron, quedando uno que fue a dar noticia a otra ranchería, los que vinieron al encuentro y nos hicieron un largo razonamiento (de lo que me quedé en ayunas por no entender nada) y contamos en todos sesenta y dos gentiles, a quienes se les dio sus abalorios y se fueron a sus rancherías. A puestas del sol formamos trinchera, se pusie-

111 Fray Juan Crespi dedicó el valle a san Juan Bautista a petición del comandante Rivera y Moncada: "esperando que con el tiempo sea una muy grande misión del santo precursor que reduzca a la santa fe a toda esta numerosa gentilidad". Fray Junípero Serra lo cristianó san Juan Capistrano. Palou: Recopilación de noticias ..., I, págs. 308 y 356. El dominico valenciano fray Luis de Sales fundó la misión de San Miguel Arcángel el 28 marzo 1787. Sobre las distintas exploraciones del área de San Miguel, véase Niesser: Las fundaciones misionales ..., págs. 185-189. Un estudio de la frontera indígena, en Zárate Loperena, Daniel: "La guerra kumiai en las postrimerías del siglo XVIII y la fundación de San Miguel”, Estudios Fronterizos, 14, Tijuana, 1987, págs. 87-97.

112 Primer encuentro pacífico con los indios kumiai, quienes habían sido avistados las jornadas anteriores. El grupo local se mostró dócil y, tras la entrega de algunos regalos: "se vinieron todos muy contentos al real, y a sus casitas que estaban inmediatas; regalando a los soldados algunas sardinas tatemadas, y diciéndonos por señas cómo habían pasado dos barcos, y según sus señas entendíamos no estaban muy lejos". Palou: Recopilación de noticias ..., I, pág. 309. Sin embargo, la aparición de otro grupo de indios rivales puso fin al encuentro. 
ron los centinelas y quedamos sin novedad ${ }^{113}$. Hoy caminamos cuatro leguas. (Al margen: 4 leguas)

Día 11. De mañana salimos por la marina en compañía de diecisiete gentiles (que al olor de los abalorios nos acompañaban), ejecutando el rumbo del nornoroeste. Dejamos la marina y los seguimos por unas lomas tendidas. Como a las cuatro de la tarde divisamos dos islas, siendo una la que vimos el día 7. A las cinco de la tarde paramos el real en otra cañada que llega a la orilla del mar, muy abastecida de árboles, con agua en poza ${ }^{114}$. Aquí vinieron unos indios de otra ranchería, a los que se les dio sus abalorios y uno de ellos tenía pendiente de la nariz un zarcillo que, según señalaba, se lo había dado la expedición de mar $^{115}$, lo que nos causó mucha alegría por tener noticias, de que tanto carecíamos. Quedamos sin novedad, hecha trinchera, con dos centinelas guardando las órdenes del capitán para de noche. Hoy caminaríamos cuatro leguas. (Al margen: 4 leguas)

Día 12. Salimos de este paraje a las ocho de la mañana, ejecutando el rumbo del nornoroeste y, habiendo caminado como dos leguas, nos vimos precisados a parar por la mucha fuerza de los indios gentiles que para ello nos hacían. Paramos el real a la inmediación de la marina ${ }^{116}$, desde donde reconocimos ser las islas que habíamos avistado las de Coronados, que se componen de cuatro islas y tres farellones, por lo que consideramos estar distantes del puerto de San Diego ocho leguas. A estos indios se les dieron sus abalorios y son muy sutiles para tratar de compra y venta, como también para hurtar, pues a dos soldados le[s] hurtaron a uno las espuelas y a otro las mangas. Quedamos sin novedad, guardando las órdenes del capitán. Caminaríamos dos leguas. (Al margen: 2 leguas)

Día 13. De mañana salimos por la orilla de la playa y, habiendo andado como una legua, vi la punta de los Guijarros sobre el puerto de San Diego, distancia de nosotros de seis a siete leguas. Seguimos la orilla y descubrimos un puerto que entraba más de cinco leguas la tierra adentro. Seguimos en su demanda, ejecutando el rumbo del noroeste, pero, habiendo encontrado un arroyo corriente, fue preciso el parar por necesitar de agua la caballada ${ }^{117}$. Vinieron unos indios al real, a los

113 El paraje fue bautizado por fray Juan Crespi como: "las pozas del valle de San Antonino", y, por su parte, fray Junípero Serra lo dedicó a san Francisco Solano. Palou: Recopilación de noticias ..., I, págs. 310 y 357 A este valle mudó el dominico fray Tomás de Ahumada la misión de San Miguel Arcángel en 1817, siendo conocida como El Descanso.

114 Fray Juan Crespi bautizó el paraje como: "el vallecito de San Pío"; mientras fray Junípero Serra lo dedicó a san Benvenuto. Palou: Recopilación de noticias ..., I, págs. 312 y 359 Se trata de la desembocadura del arroyo Rosarito.

115 Los primeros trabajos en San Diego fueron estudiados por Wilson Engstrand, Iris: "The Occupation of the Port of San Diego de Alcalá, 1769”, en The Journal of San Diego History, vol. XXIV, n. ${ }^{\circ}$ 1, San Diego, 1978, págs. 91-96.

116 El paraje fue bautizado por fray Juan Crespi como: "la pocita de la ranchería de los Santos Mártires Nereo y sus compañeros"; y fray Junípero Serra, La Cárcel de San Pedro, cuya fiesta se celebraba en ese día. Palou: Recopilación de noticias ..., I, págs. 313 y 361

117 Fray Juan Crespi lo llamó: "la ranchería y arroyo de Sancti Spiritus" por celebrarse al día siguiente la Pascua del Espíritu Santo. Palou: Recopilación de noticias ..., I, pág. 314. Se trata del río Tijuana, donde se sitúa la actual frontera entre los Estados Unidos y México. 
que se les dio sus abalorios. Quedamos sin novedad, mas que con gran cuidado por haber cargado mucha indiada. Hicimos la trinchera y se pusieron los centinelas. Hoy caminamos una legua y media. (Al margen: una legua y media).

Cuando llegaron los indios al real, hizo uno, que debía ser el capitán de los gentiles, un gran razonamiento, y otro indio puso la flecha en el arco para tirar a un soldado, que, a no haber estado el capitán y su gente con el cuidado que acostumbran, pudiera haber sucedido alguna desgracia. Toda la tierra pinta hasta el puerto de San Diego muy llana y abundante de zacate. En este paraje no tuvimos leña para hacer tortillas y dispuso el capitán quemaran los palos de su tienda de campaña.

Día 14 de mayo. Pascua de Espíritu Santo. Nos amaneció lloviendo y, habiendo cesado el agua, salimos a las diez en demanda del puerto de San Diego. Habiendo caminado como una legua, tuvimos el gusto de divisar los dos paquebotes San Carlos y El Príncipe fondeados en el puerto. Seguimos en su demanda contra el gusto de los gentiles, que nos hacían fuerza a que parásemos en su ranchería. Habiendo caminado seis leguas, llegamos al paraje donde estaban las embarcaciones, a las que les hicimos saludo, y nos correspondieron de los buques y de las barracas que estaban en tierra, a las que llegamos a las cinco de la tarde y tuvimos la noticia de que toda la expedición marítima estaba enferma del escorbuto. Paramos el real y el día siguiente, 15 de mayo, fuimos con la noticia que teníamos de un río que se halla en este puerto a sus inmediaciones, lo que ejecutamos parando el real con atrincheramiento. Se dispuso fueran los enfermos de los barcos al paraje donde nos hallábamos alojados, lo que se hizo el día 17. (Al margen: 6 leguas)

Desde el día 18 de mayo hasta el 28 de junio se ha estado la compañía de don Fernando de Ribera asistiendo a las faenas de los barcos y descarga del Príncipe, habiéndose hecho algunos jacales para la gente [y] un corral para la caballada, no habiéndose podido establecer la misión ${ }^{118}$ por causa de haber estado este tiempo en las faenas mencionadas. El día 29 llegó el caballero gobernador ${ }^{119}$, el que ha dispuesto seguir por tierra, sin embargo del atraso de los barcos, dejando en la misión que se empieza a establecer una escolta de ocho soldados.

Por este diario queda averiguado el estar distante este puerto de la nueva misión de Vilacatá ciento veintiuna leguas, habiendo experimentado, visto y reconocido todo lo que llevo expuesto en este diario, el que queda finalizado hasta el día 3 de julio del año de 1769. Joseph de Cañizares.

118 La misión de San Diego de Alcalá fue fundada el 16 de julio de 1769 por fray Junípero Serra.

119 Gaspar de Portolá tuvo que afrontar numerosas dificultades, pero sus méritos no tuvieron una recompensa inmediata, siendo relevado del gobierno de California tras tomar posesión de San Diego y Monterrey. Véase, Bernabéu Albert, Salvador: "El virrey de Californias. Gaspar de Portolá y la problemática de la primera gobernación californiana (1768-1771)", en Revista de Indias, 195-196, Madrid, 1992, págs. 271-295. 